\title{
Un nuevo estilo de gestión para los espacios naturales protegidos en Andalucía
}

\author{
$M^{a}$ Remedios Zamora Roselló \\ Profesora Ayudante-Doctor de Derecho Administrativo \\ Universidad de Málaga
}

\begin{abstract}
SUMARIO: I. CONTEXTO: 1. La Directiva 2006/123/CE. 2. La transposición a nivel nacional. 3. El nuevo marco regulador de la Comunidad Autónoma de Andalucía.- II.- EL DECRETO 15/2011 SOBRE LOS PARQUES NATURALES ANDALUCES: 1. Finalidad. 2. Estructura y contenido. 3. Clasificación de actividades. 4.- Competencias de las Juntas Rectoras de los Parques Naturales y de las Consejerías implicadas.- III.- CONSIDERACIONES FINALES.
\end{abstract}

\section{RESUMEN:}

La aprobación del Decreto 15/2011 ha generado un profundo debate sobre el modelo de gestión de los parques naturales andaluces. En este trabajo se analizan los orígenes de la norma, con referencia a las disposiciones de la Unión Europea; y posteriormente se acomete un profundo estudio de cada uno de los preceptos del Decreto, con especial referencia a los procedimientos de autorización y comunicación previa y a los órganos competentes en el ámbito de la Administración autonómica, y las distintas valoraciones que ha merecido la norma andaluza.

Palabras clave: Directiva de servicios, desarrollo sostenible, gestión de los espacios naturales, simplificación de los procedimientos administrativos, libertad de establecimiento y de circulación de servicios, calidad del medio ambiente.

ABSTRACT:

The adoption of Decree 15/2011 has generated a serious debate on the management model of the Andalusia natural parks. This paper discusses the origins of the rule, with reference to the provisions of the European Union; and then, it undertakes a thorough study of each of the provisions of the Decree, with special reference to the procedures for authorisation and prior 
notification and bodies in the field of Regional Administration, and the different assessments of the Andalusia rule.

Key words: Directive on services in the internal market, sustainable development, management of natural areas, simplify administrative procedures, freedom of establishment and free movement of services, quality of the environment.

\section{CONTEXTO}

\section{La Directiva 2006/123/CE}

La primera idea que es necesario destacar es que el Decreto 15/2011 de 1 de febrero se elabora en un contexto marcado por las dificultades económicas. Por ello, si bien esta norma se dicta en virtud de las competencias autonómicas en materia de medio ambiente previstas en el Estatuto de Autonomía para Andalucía ${ }^{1}$, su finalidad última también comprende el impulso a la actividad económica y la agilización y simplificación de los procedimientos administrativos autonómicos².

${ }^{1}$ El artículo 28.2 del Estatuto de Autonomía de Andalucía (EAA) establece que se garantiza el derecho al medio ambiente "mediante una adecuada protección de la diversidad biológica y los procesos ecológicos, el patrimonio natural, el paisaje, el agua, el aire y los recursos naturales". Según lo previsto en el art. 37.1.20 EAA, entre los principios rectores que orientarán las políticas públicas se encuentra "el respeto del medio ambiente, incluyendo el paisaje y los recursos naturales y garantizando la calidad del agua y del aire". En lo que respecta a las competencias autonómicas, el art. 57.1 EAA afirma que "corresponde a la Comunidad Autónoma la competencia exclusiva, sin perjuicio de lo dispuesto en el artículo 149.1.23 de la Constitución, en materia de: montes, explotaciones, aprovechamientos y servicios forestales; vías pecuarias; marismas y lagunas, y ecosistemas acuáticos; pastos y tratamiento especial de zonas de montaña; delimitación, regulación, ordenación y gestión integral de los espacios naturales protegidos, incluyendo los que afecten a las aguas marítimas de su jurisdicción, corredores biológicos, y hábitats en el territorio de Andalucía, así como la declaración de cualquier figura de protección y establecimiento de normas adicionales de protección ambiental; fauna y flora silvestres; prevención ambiental". Sobre esta materia cabe remitirse a JORDANO FRAGA, J., "Política ambiental de Andalucía" en LÓPEZ RAMÓN, F. (Coord), Observatorio de Políticas Ambientales 2007, Ministerio de Medio ambiente, Thomson-Aranzadi, Pamplona, 2007, pp. $261-285$.

${ }^{2}$ En la Exposición de Motivos del Decreto no se incluye referencia alguna a las competencias autonómicas en materia económica, mientras que sí se menciona el art. 47.1 EAA en el que se reconoce la competencia exclusiva de la Comunidad Autónoma sobre "el procedimiento administrativo derivado de las especialidades de la organización propia de la Comunidad Autónoma, la estructura y regulación de los órganos administrativos públicos de Andalucía y de sus organismos autónomos". 
La Directiva 2006/123/CE, de Servicios y las normas estatal y autonómica que la desarrollan constituyen uno de los pilares sobre los que se asienta el Decreto $^{3}$. Como sabemos, el objeto de la Directiva de Servicios es establecer las disposiciones generales necesarias para facilitar el ejercicio de la libertad de establecimiento de los prestadores de servicios y la libre circulación de los servicios, manteniendo, al mismo tiempo, un nivel elevado de calidad. La consecución de un auténtico mercado interior de servicios guía cada uno de los preceptos de la norma comunitaria.

Un destacado número de las decisiones más polémicas del Decreto andaluz tienen su origen en la Directiva comunitaria, por lo que si bien el propósito de este estudio no es analizar en profundidad esta disposición, resulta imprescindible exponer algunas de sus aportaciones esenciales.

La Directiva 2006/123/CE se compone de 118 considerandos y su articulado se estructura en ocho capítulos. Sin perjuicio de la relevancia del primer capítulo, en el que se exponen las disposiciones generales y que incluye las referencias al objeto, ámbito de aplicación y a las definiciones empleadas, para nuestro estudio resultan de especial interés los capítulos segundo y tercero, que versan sobre la simplificación administrativa y la libertad de establecimiento de los prestadores.

El exceso de trámites administrativos es una de las causas que actúan como freno en el desarrollo de las actividades de servicios en los Estados miembros. El concepto clave que trata de incorporar la norma comunitaria en los procedimientos administrativos es la simplificación. Como se señala en el considerando $42^{\circ}$, la finalidad no es armonizar los procedimientos administrativos, sino "suprimir los regímenes de autorización, procedimientos y formalidades excesivamente onerosos". La norma comunitaria identifica la modernización y la implantación de los principios de buena administración con la simplificación administrativa, y la consecuente limitación de las autorizaciones previas obligatorias ${ }^{4}$.

\footnotetext{
${ }^{3}$ Directiva 2006/123/CE, del Parlamento Europeo y del Consejo, de 12 de diciembre de 2006, relativa a los servicios en el mercado interior (DOUE, 376 L, de 27 de diciembre de 2006). Ley 17/2009, de 23 de noviembre, sobre el libre acceso a las actividades de servicios y su ejercicio, (BOE, núm. 283, de 24 de noviembre de 2009); Ley 3/2010, de 21 de mayo, por la que se modifican diversas leyes para la transposición en Andalucía de la Directiva 2006/123/CE, de 12 de diciembre de 2006, del Parlamento Europeo y del Consejo, relativa a los servicios en el mercado interior (BOJA, núm. 111, de 8 de junio de 2010).

${ }^{4}$ En el considerando $43^{\circ}$ de la Directiva se afirma: "procede establecer principios de simplificación administrativa, en concreto limitando la autorización previa obligatoria a aquellos casos en que sea indispensable e introduciendo el principio de autorización tácita de las autoridades competentes una vez vencido un plazo determinado. El objetivo de este tipo de acción de modernización es, aparte de garantizar los requisitos de transparencia y actualización de los datos relativos a los operadores, eliminar los retrasos,
} 
La Directiva impone a los Estados la obligación de comprobar que los procedimientos y formalidades de acceso a una actividad de servicios y a su ejercicio sean lo suficientemente simples, instando a su simplificación cuando se detecten irregularidades. En los considerandos se establecen una serie de principios que deben ser tenidos en cuenta por los Estados a la hora de realizar este examen; en particular deberán atender a su necesidad, número, posible duplicación, costes, claridad y accesibilidad, así como a las dificultades prácticas y retrasos que podrían generarse.

La regulación de las autorizaciones administrativas también constituye una pieza clave en las novedades introducidas por la Directiva ${ }^{5}$. El régimen de las autorizaciones es restrictivo, y sólo se podrá supeditar el acceso a una actividad de servicios a su previa obtención cuando se considere una medida no discriminatoria, necesaria (interés general) y proporcionada (imposibilidad de control a posteriori $)^{6}$.

La posible arbitrariedad de las autoridades competentes es una de las grandes preocupaciones del texto comunitario; con el fin de controlar el carácter subjetivo en la apreciación de los requisitos necesarios para la concesión de la autorización se imponen una serie de criterios que delimiten la facultad de apreciación de estas autoridades. Los criterios deben ser: no discriminatorios, justificados por una razón imperiosa de interés general, proporcionados, claros

costes y efectos disuasorios que ocasionan, por ejemplo, trámites innecesarios o excesivamente complejos y costosos, la duplicación de operaciones, las formalidades burocráticas en la presentación de documentos, el poder arbitrario de las autoridades competentes, plazos indeterminados o excesivamente largos, autorizaciones concedidas con un período de vigencia limitado o gastos y sanciones desproporcionados. Este tipo de prácticas tienen efectos disuasorios especialmente importantes para los prestadores que deseen desarrollar sus actividades en otros Estados miembros y requieren una modernización coordinada en un mercado interior ampliado a veinticinco Estados miembros". Sobre los principios que inspiran la Directiva comunitaria, RASTROLLO SUÁREZ, J., "Directiva de servicios: urbanismo, medio ambiente y agricultura", Revista de derecho urbanístico y medio ambiente, núm. 259, 2010, pp. 135-172; RUBALCABA, L. y VISINTIN, S., "The internal market for services", en RUBALCABA, L., The new service economy, Edward Elgar Publishing, Cheltenham, Reino Unido, 2007.

${ }^{5}$ En relación a las novedades de la Directiva comunitaria, SÁNCHEZ ARMAS, T., "El régimen de autorizaciones en la Directiva de Servicios. ¿Hacia un nuevo Derecho Administrativo?”, en Retos y oportunidades para la transposición de la Directiva de Servicios, Libro Marrón, Círculo de Empresarios, Madrid, 2009, pp. $405-432$.

${ }^{6}$ Art. 9.1 de la Directiva 2006/123/CE. Como señala LAGUNA DE PAZ: "se trata de exigencias elementales, que se desprenden de la libertad de empresa (art. $38 \mathrm{CE}$ ) y del principio de buena administración que recoge nuestra Constitución (art. 103.1 CE). Cuestión distinta es que el legislador no siempre se haya dejado iluminar por los principios constitucionales. De ahí la oportunidad de la norma comunitaria, que viene a reforzar la exigencia de su aplicación”. LAGUNA DE PAZ, J., "Controles administrativos para el acceso al mercado: autorizaciones, declaraciones responsables y comunicaciones previas", en VICENTE BLANCO, D., y RIVERO ORTEGA, R. (Dir.), Impacto de la transposición de la Directiva de servicios en Castilla y León, Consejo Económico y Social de Castilla y León, Valladolid, 2010, pp. 316. 
e inequívocos, objetivos, hechos públicos con antelación, transparentes y accesibles. En esta misma línea toda decisión de las autoridades competentes, así como la denegación o la retirada de la autorización, deberán ser motivadas y podrán ser impugnadas mediante los recursos que correspondan.

La relación entre la Directiva de Servicios y el medio ambiente se determina desde los propios considerandos de la norma comunitaria. La coordinación de las legislaciones nacionales se encuentra condicionada por un nivel elevado de protección de los objetivos de interés general, entre los que se menciona expresamente a la protección de los consumidores, la protección del medio ambiente, la seguridad pública y la salud pública, y la necesidad de ajustarse al Derecho del trabajo ${ }^{7}$.

La protección del medio ambiente es un objetivo transversal en todas las iniciativas comunitarias, y se materializa como limitador e impulsor de las actividades previstas en la Directiva de Servicios. La regulación específica sobre protección del medio ambiente también influye directamente en el sector servicios, por lo que las propuestas de futuro de las instituciones comunitarias instan a una coodinaciónr real para potenciar un mercado único de servicios, efectivo $\mathrm{y} \sin$ fisuras en todos los Estados miembros ${ }^{8}$.

En su perspectiva limitadora, la protección del medio ambiente es uno de los motivos tasados que los Estados pueden aplicar para condicionar la libre prestación de servicios. Los Estados miembros pueden supeditar el acceso a una actividad de servicios o su ejercicio en su territorio al cumplimiento de principios no disciminatorios, proporcionales y necesarios, entre éstos últimos se hace referencia expresa a la protección del medio ambiente ${ }^{9}$.

\footnotetext{
7 Considerando $7^{\circ}$.

${ }^{8}$ La Comisión Europeaen se pronuncia en los siguientes términos en su su Comunicación al Parlamento Europeo, al Consejo, al Comité Económico y Social Europeo y al Comité de las Regiones titulada Hacia un mejor funcionamiento del mercado único de servicios, partiendo de los resultados del proceso de evaluación recíproca de la Directiva de servicios, COM (2011) 20 final, de 27 de enero de 2011, pp. 13: "La implementación de la Directiva de servicios es un importante paso de cara a un mejor funcionamiento del mercado único de servicios. No obstante, aún queda camino por recorrer. Partiendo del proceso de evaluación recíproca de la Directiva de servicios, la presente Comunicación propone una serie de actuaciones cuya finalidad última es profundizar en el mercado único de servicios y aproximarlo más a las necesidades de las empresas y los ciudadanos. Es esta una responsabilidad compartida y el éxito de esas actuaciones dependerá del compromiso de todas las instituciones y todos los interesados involucrados".

${ }^{9}$ Art. 16. En el Manual sobre la transposición de la Directiva de servicios elaborado por la Comisión Europea (pág. 41), se afirma con respecto a este precepto: "los estados miembros tienen la posibilidad de garantizar que los prestadores de servicios cumplan con sus respectivas normas nacionales, regionales o locales
} 
Entre las razones imperiosas de interés general que se enumeran en la Directiva se encuentra la protección del medio ambiente y del entorno urbano. Estas razones imperiosas se consideran de tal relevancia que pueden llevar aparejadas la aplicación de principios contrarios al espíritu de la norma; de esta forma se justifica la exigencia de requisitos formales como la presentación de copias o traducciones compulsadas, que contradicen la voluntad de incentivar la simplificación administrativa. En el mismo sentido, pueden ser exigencias de protección ambiental las que justifiquen una autorización individual para cada establecimiento o una limitación de la autorización a un lugar específico del territorio nacional; en contraposición a la regla general que exige una sola autorización para dar acceso a una actividad de servicios o a su ejercicio en todo el territorio nacional ${ }^{10}$.

La protección ambiental actúa como elemento a favor para la concesión de una autorización para una actividad. En aquellos supuestos en los que exista un número limitado de autorizaciones, por razón de la escasez de recursos naturales o de las capacidades técnicas que se pueden utilizar, los Estados miembros aplicarán un procedimiento de selección entre los posibles candidatos en el que se podrá favorecer a aquellos que cumplan con objetivos de protección del medio ambiente ${ }^{11}$.

El intercambio de información y la coordinación entre todos los Estados miembros también se materializa en la activación de mecanismos de alerta cuando cualquier Estado detecte que una actividad pueda ocasionar un perjuicio grave para el medio ambiente; en estos casos informará a la Comisión y al resto de Estados afectados. Asimismo, cuando un Estado miembro tenga un

sobre protección del medio ambiente. teniendo en cuenta las características específicas del lugar en el que se prestan los servicios, los estados miembros pueden evitar que éstos repercutan negativamente en el medio ambiente del lugar en cuestión. tales normas pueden aludir a la protección contra la contaminación acústica (niveles máximos de ruido respecto al uso de cierta maquinaria), al uso de sustancias peligrosas con vistas a la prevención de daños al medio ambiente, a la eliminación de residuos producidos en el curso de una actividad de servicios, etc. en todos estos casos ha de examinarse con detenimiento si la aplicación de los requisitos del estado miembro anfitrión es necesaria y proporcionada. por ejemplo, puede que un prestador sea objeto ya de auditorías medioambientales en su estado miembro de establecimiento para determinar la idoneidad medioambiental de su explotación y de sus métodos de trabajo y los requisitos vigentes en el estado miembro anfitrión no deberán dar lugar a un solapamiento de normas en este terreno".

${ }^{10}$ Art. 4 y Considerandos $40^{\circ}$ y $47^{\circ}$. En esta línea, SANZ RUBIALES, I., "Medio Ambiente y Directiva de Servicios en Castilla y León", en VICENTE BLANCO, D., y RIVERO ORTEGA, R. (Dir.), Impacto de la transposición de la Directiva de servicios en Castilla y León, Consejo Económico y Social de Castilla y León, Valladolid, 2010, pp. 599-625.

11 Art. 11. 
conocimiento real de un comportamiento o de hechos concretos de un prestador, establecido en su territorio y que preste servicios en otros Estados miembros, que puedan causar un perjuicio grave para el medio ambiente, informará de ello lo antes posible a todos los Estados miembros y a la Comisión ${ }^{12}$.

La norma comunitaria excepciona de la libre prestación de servicios a diversos sectores vinculados directamente con la protección del medio ambiente; la Directiva incluye entre las excepciones una serie de servicios de interés económico general, y menciona expresamente a los servicios de distribución y suministro de agua y los servicios de aguas residuales, así como al tratamiento de residuos. Además, se incluye entre las excepciones el transporte de residuos, ya que el reglamento que regula esta materia contiene una serie de normas que establecen obligaciones que han de cumplirse en el país de destino o de tránsito, y el legislador comunitario garantiza con esta previsión que no se vean afectadas por el contenido de la Directiva ${ }^{13}$.

\section{La transposición a nivel nacional}

La transposición a nivel nacional de la Directiva 2006/123/CE se ha materializado a través de dos normas: la Ley 17/2009, de 23 de noviembre, encargada de regular los principios de la intervención de las Administraciones Públicas en el sector de los servicios y simplificar los procedimientos administrativos, y la Ley 25/2009, de 22 de diciembre, mediante la que se han modificado diversas normas con rango de ley para adaptarlas a las previsiones comunitarias y se diseñan medidas de dinamización para el sector servicios ${ }^{14}$.

\footnotetext{
12 Arts. 12 y 29.

13 Art. 18. COMISIÓN EUROPEA, Manual..., op. cit., pp. 45.

14 Sobre las novedades de la Directiva de Servicios y su transposición al derecho español: DE LA CUADRA SALCEDO JANINI, T., ¿Quo vadis Bolkestein?, ¿Armonización o mera desregulación de la prestación de servicios?”, Revista Española de Derecho Europeo, núm. 22, 2007, pp. 237-280; FERNÁNDEZ, T. R., "Un nuevo Derecho Administrativo para el mercado interior europeo", Revista Española de Derecho Europeo, núm. 22, 2007, pp. 189-197; PAREJO ALFONSO, L., "La desregulación de los servicios con motivo de la Directiva Bolkestein: la interiorización, con paraguas y en ómnibus de su impacto en nuestro sistema”, El cronista del Estado Social y Democrático de Derecho, núm. 6, 2009, pp. 34-41; RIVERO ORTEGA, R., La transposición de la Directiva de Servicios en España, Civitas, Madrid, 2009; VILLAREJO GALENDE, H. y SALVADOR ARMENDÁRIZ, M., "El complejo proceso de transposición de la Directiva de Servicios", en Informe Comunidades Autónomas 2008, Instituto de Derecho Público, Barcelona, 2009, pp. 81-122.

En este mismo sentido corresponde remitirse a las Exposiciones de Motivos de las normas de transposición españolas. En la Exposición de Motivos de la Ley 17/2009 se afirma: "El objeto de esta Ley es, pues, establecer las disposiciones y principios necesarios para garantizar el libre acceso a las actividades de servicios y su ejercicio realizadas en territorio español por prestadores establecidos en España o en cual-
} 
La Ley 25/2009 introdujo un nuevo precepto en la Ley 30/1992 de Régimen Jurídico de las Administraciones Públicas y del Procedimiento Administrativo Común (LRJPAG), con el fin de ofrecer dos técnicas alternativas a la autorización: la declaración de responsabilidad y la comunicación previa ${ }^{15}$. Mediante la declaración de responsabilidad el interesado manifiesta de manera expresa, clara y precisa que cumple con los requisitos establecidos en la normativa vigente para acceder al reconocimiento de un derecho o facultad o para su ejercicio, dispone de la documentación que así lo acredita, y se compromete a mantener su cumplimiento durante el periodo de tiempo inherente a dicho reconocimiento o ejercicio. A través de la comunicación previa el interesado informa a la Administración Pública sus datos identificativos y demás requisitos exigibles para el ejercicio de un derecho o el inicio de una actividad.

La regulación de estas figuras debe completarse con lo dispuesto en la legislación específica, si bien la LRJPAC establece una serie de previsiones que permiten establecer pautas comunes en su régimen jurídico: a) Pueden producir efectos desde el día de su presentación, por lo que producirán el reconocimiento o ejercicio de un derecho o bien el inicio de una actividad, e incluso la comunicación podrá presentarse dentro de un plazo posterior al inicio de la ac-

\footnotetext{
quier otro Estado miembro de la Unión Europea, simplificando los procedimientos y fomentando al mismo tiempo un nivel elevado de calidad en los servicios, promoviendo un marco regulatorio transparente, predecible y favorable para la actividad económica, impulsando la modernización de las Administraciones Públicas para responder a las necesidades de empresas y consumidores y garantizando una mejor protección de los derechos de los consumidores y usuarios de servicios". El objetivo de la Ley 25/2009 se expone en su Exposición de Motivos en los siguientes términos: "En primer lugar, adapta la normativa estatal de rango legal a lo dispuesto en la Ley 17/2009, de 23 de noviembre, sobre el libre acceso a las actividades de servicios y su ejercicio, en virtud del mandato contenido en su Disposición final quinta. En segundo lugar, con objeto de dinamizar en mayor medida el sector servicios y de alcanzar ganancias de competitividad en relación con nuestros socios europeos, extiende los principios de buena regulación a sectores no afectados por la Directiva, siguiendo un enfoque ambicioso que permitirá contribuir de manera notable a la mejora del entorno regulatorio del sector servicios y a la supresión efectiva de requisitos o trabas no justificados o desproporcionados. El entorno regulatorio resultante de la misma, más eficiente, transparente, simplificado y predecible para los agentes económicos, supondrá un significativo impulso a la actividad económica".

${ }^{15}$ Art. 71 bis LRJPAC. En relación al procedimiento administrativo a la vista de la Directiva de servicios y su transposición en nuestro país: RAZQUIN LIZARRAGA, J., "El impacto de la Directiva de Servicios en el procedimiento administrativo: autorización, declaración responsable y comunicación", Revista jurídica de Navarra, núm. 49, 2010, pp. 85-136; RIVERO ORTEGA, R., "Reformas de Derecho Administrativo para 2010: la difícil transposición de la Directiva de Servicio s en España", Revista Aragonesa de Administración Pública, núm. 34, 2009, pp. 51-80; MUÑOZ MACHADO, S., "Ilusiones y conflictos derivados de la Directiva de Servicios", Revista General de Derecho Administrativo, núm. 21, 2009; SÁNCHEZ GUTIÉRREZ, M., "La transposición de la Directiva de Servicios al Ordenamiento español. Especial referencia a los cambios previstos en la regulación del sector del gas natural", Revista General de Derecho Administrativo, núm. 22, 2009.
} 
tividad; b) La Administración conserva las facultades de comprobación, control e inspección; c) La inexactitud, falsedad u omisión, de carácter esencial, o la no presentación ante la Administración competente de la declaración responsable o comunicación previa, determinará la imposibilidad de continuar con el ejercicio del derecho o actividad afectada, sin perjuicio de las responsabilidades penales, civiles o administrativas; la resolución de la Administración Pública que declare tales circunstancias podrá determinar la obligación del interesado de restituir la situación jurídica al momento previo al reconocimiento o al ejercicio del derecho o al inicio de la actividad correspondiente, así como la imposibilidad de instar un nuevo procedimiento con el mismo objeto durante un periodo de tiempo determinado; d) Las Administraciones Públicas tendrán permanentemente publicados y actualizados modelos de declaración responsable y de comunicación previa.

Siguiendo el mismo modelo de análisis aplicado a la Directiva, nos vamos a centrar en el estudio de las consecuencias sobre el medio ambiente de estas disposiciones de transposición. La Ley 17/2009, aplicando las directrices comunitarias, permite supeditar la libre prestación de servicios al cumplimiento de los requisitos que en cada caso determine la legislación sectorial cuando estén justificados por razones de protección del medio ambiente; estos requisitos deberán ser proporcionados, no discriminatorios y estar suficientemente motivados. Esta norma también faculta a las Administraciones Públicas a otorgar autorizaciones o solicitar comunicaciones o declaraciones responsables a los prestadores con eficacia limitada a una parte específica del territorio, siempre que esté justificado por razón de la protección del medio ambiente y sea una medida motivada, proporcionada y no discriminatoria ${ }^{16}$.

A pesar de estas previsiones la Ley 25/2009 regula una serie de supuestos en los que se instaura la comunicación previa aún cuando podría encontrarse comprometida la protección del medio ambiente. Podemos destacar la regulación sobre la gestión de residuos, que impone el deber a los titulares de actividades que desarrollen operaciones de gestión de residuos no peligrosos distintas a la valorización o eliminación, de comunicarlo para su registro ante el órgano ambiental competente de la Comunidad Autónoma donde tengan su se$\mathrm{de}^{17}$. En este mismo sentido cabe citar la reforma de la regulación sobre vías pecuarias, donde se sustituye la autorización por la declaración responsable ${ }^{18}$.

\footnotetext{
16 Art. 7.3 de la Ley 17/2009.

17 Art. 32.4 de la Ley 25/2009, sobre la modificación de la Ley 10/1998, de 21 de abril, de Residuos.

18 Art. 31 de la Ley 25/2009, sobre la modificación de la Ley 3/1995, de 23 de marzo, de Vías Pecuarias.
} 
La Ley 25/2009 también ha introducido novedades en la regulación sobre los procedimientos de autorización y concesión de actividades de servicios en los parques nacionales, reconociendo la aplicación de los principios de publicidad, objetividad, imparcialidad y transparencia, y del principio de concurrencia competitiva cuando la actividad se promueva por la administración gestora del parque y en aquellos supuestos en los que el ejercicio de la actividad excluya el ejercicio de otras actividades por terceros. Estas concesiones y autorizaciones serán de duración determinada en función de sus características, y en ningún caso la renovación será automática. La protección del medio ambiente regirá todos los criterios del procedimiento para estas concesiones y autorizaciones. En los mismos términos y con idénticas previsiones se ha modificado la Ley del Patrimonio Natural y de la Biodiversidad, en relación al ejercicio de las actividades de servicios que requieran autorizaciones o concesiones ${ }^{19}$.

La configuración de la declaración de responsabilidad y la posibilidad de presentar la comunicación previa con posterioridad al inicio de la actividad plantean un nuevo modelo de actuación de la Administración que exige un fortalecimiento de los controles posteriores. En este sentido conviene atender a las facultades de inspección de las Administraciones públicas que deberán potenciarse para que el grado de cumplimiento de los requisitos exigidos se mantenga; asimismo, debe llevar aparejado un endurecimiento del régimen sancionador que permita disuadir de los posibles incumplimientos. La desaparición de autorizaciones, en definitiva de controles previos, que obstaculizan la implantación y el desarrollo de nuevas actividades también tendrá que venir modulada por su potencial de daños; en ningún caso podrá suprimirse la autorización cuando se trate de actividades que puedan ocasionar graves daños ${ }^{20}$. Esta realidad adquiere mayor relevancia en el ámbito de la protección y conservación de los espacios naturales, donde la alteración del equilibrio de los ecosistemas puede traducirse en un daño irreparable para el entorno.

${ }^{19}$ Art. 35 de la Ley 25/2009, sobre la modificación de la Ley 5/2007, de 3 de abril, de la Red de Parques Nacionales. Art. 36 de la Ley 25/2009, sobre la modificación de la Ley 42/2007, de 13 de diciembre, del Patrimonio Natural y de la Biodiversidad.

${ }^{20}$ En este sentido se ha manifestado LAGUNA DE PAZ, op. cit., pp. 321-322. Este autor pone de relieve la contradicción existente cuando se exige una declaración responsable o una comunicación para el acceso a una actividad o su ejercicio y una evaluación de impacto ambiental. Como afirma esta autora: "Cabe preguntarse, no obstante, si en aquellos s upuestos en los que se exige una evaluación de impacto ambiental para determinada actividad no queda ya por ello acreditada la concurrencia de una razón im periosa de interés general vinc ulada a la pro tección del medio ambiente que, del mismo modo que justifica el som etimiento al procedimiento de EIA, requeriría un control a priori mediante autorización. Por ot ro lado, interesa señalar que esta prescripción exigirá revisar la doctrina jurisprude ncial que considera que la Declaración de Impacto Ambiental es un mero acto de trámite y no resulta recurrible por sí sólo 
La eliminación de los controles previos y de cualquier otro tipo de obstáculo para la libre prestación de servicios se encuentra condicionada, desde las previsiones de la Directiva y en la propia transposición española, por la protección del medio ambiente ${ }^{21}$. La supresión de las medidas de control, que si bien es verdad que obstaculizan el desarrollo del sector servicios tampoco podemos obviar que suponen una garantía para la protección del entorno natural, no puede realizarse sin un sistema alternativo para el respeto de los fines de interés general ${ }^{22}$. En buena parte de las modificaciones normativas realizadas al amparo de la Directiva de Servicios tan sólo se ha atendido a la supre-

(...)". LOZANO CUTANDA, B., "Ley omnibus: una revolución en las técnicas de intervención administrativa (silencio positivo, declaración responsable y comunicación previa)", Working Paper IE Law School, AJ8-161, 25 de marzo de 2010, pp. 16. Como han señalado ARANA GARCíA, E., y GRANADOS RODRÍGUEZ, J., en "La desaparición de las licencias en las actividades clasificadas incluidas en el ámbito de la directiva de servicios: el supuesto particular de la legislación ambiental andaluza", Revista General de Derecho Administrativo, núm. 25, 2010, pp. 10: "el acceso y ejercicio de servicios (entiéndase, actividades) con incidencia ambiental incluidos en el ámbito de la DS, por esa mera circunstancia, no quedan sujetos automáticamente a un régimen de autorización, sino que ello dependerá -en aplicación del principio de proporcionalidad- de que su grado de influencia en el medio ambiente justifique ese medio de intervención como el más adecuado para su protección”.

${ }^{21}$ Según lo dispuesto por TJCE, en Sentencia de 11 de marzo de 2010, Caso Attanasio Group Srl contra comune di Carbognano, apartados 50 y 51: "La jurisprudencia del Tribunal de Justicia ha identificado cierto número de razones imperiosas de interés general que pueden justificar restricciones a libertades fundamentales garantizadas por el Tratado. Entre tales razones figuran los objetivos de seguridad vial (véanse, en particular, las sentencias de 5 de octubre de 1994, Van Schaik, C-55/93, Rec. p. I-4837, apartado 19, y de 15 de marzo de 2007, Comisión/Finlandia, C-54/05, Rec. p. I-2473, apartado 40 y jurisprudencia citada), la protección del medio ambiente (véanse, en especial, las sentencias de 20 de septiembre de 1988, Comisión/Dinamarca, 302/86, Rec. p. 4607, apartado 9, y de 14 de diciembre de 2004, Radlberger Getränkegesellschaft y S. Spitz, C-309/02, Rec. p. I-11763, apartado 75) y la protección de los consumidores (véanse, en particular, las sentencias de 4 de diciembre de 1986, Comisión/Francia, 220/83, Rec. p. 3663, apartado 20; CaixaBank France, antes citada, apartado 21, y de 29 de noviembre de 2007, Comisión/Austria, C-393/05, Rec. p. I-10195, apartado 52 y jurisprudencia citada). No obstante, procede recordar que, independientemente de que exista un objetivo legítimo con arreglo al Derecho de la Unión, la justificación de una restricción de las libertades fundamentales garantizadas por el Tratado presupone que la medida de que se trate pueda garantizar el alcance del objetivo que persigue y no vaya más allá de lo necesario para alcanzar el objetivo perseguido (véanse, en ese sentido, las sentencias de 26 de noviembre de 2002 , Oteiza Olazábal, C-100/01, Rec. p. I-10981, apartado 43; de 16 de octubre de 2008, Renneberg, C-527/06, p. I-7735, apartado 81; de 11 de junio de 2009, X y Passenheim-van Schoot, C-155/08 y C-157/08, Rec. p. I-0000, apartado 47, y de 17 de noviembre de 2009, Presidente del Consiglio dei Ministri, C-169/08, Rec. p. I-0000, apartado 42). Además, una normativa nacional sólo es adecuada para garantizar la consecución del objetivo alegado si responde verdaderamente al empeño por hacerlo de forma congruente y sistemática (véanse, en particular, las sentencias antes citadas Hartlauer, apartado 55, y Presidente del Consiglio dei Ministri, apartado 42)".

${ }^{22}$ El Dictamen 779/2009 sobre el Anteproyecto de Ley de modificación de diversas Leyes para su adaptación a la Ley sobre el libre acceso a las actividades de servicios y su ejercicio, elaborado por el Consejo de Estado, se pronuncia en los siguientes términos: "el centro de gravedad de la regulación proyectada lo constituyen la elimina-

\section{Revista Andaluza de Administración Pública}


sión de las barreras, pero no se han examinado las consecuencias que pueden acarrear para la protección del medio ambiente; también cabe destacar que esta supresión de controles previos no ha alcanzado las cotas de eficacia impuestas desde la Directiva comunitaria, como ya ha tenido oportunidad de analizar el Tribunal de Justicia de las Comunidades Europeas ${ }^{23}$.

Fortalecer las labores de inspección permitiría reconducir todos los medios personales y materiales que las distintas Administraciones públicas estaban dedicando a los controles previos; esta función de inspección también se encontraría acompañada de una labor de asesoramiento y supervisión por parte de los empleados públicos. La inspección no sólo debe llevar aparejada un inelu-

ción de trabas o cargas administrativas y la supresión de numerosos regímenes de autorización, en ocasiones sustituidos por otros menos gravosos, como son la obligación de presentar una declaración responsable (telecomunicaciones, vías pecuarias, mercado del tabaco, prevención de riesgos laborales...) o una comunicación previa (servicios postales, autoescuelas que impartan exclusivamente clases teóricas...). Sin embargo, estas medidas no siempre van acompañadas del correspondiente aumento de los mecanismos de control a posteriori de la actividad, ni de un correlativo refuerzo de la protección de los derechos de los consumidores y usuarios o del fomento de la calidad de los servicios". En este sentido, FERNÁNDEZ TORRES, J., "Regímenes de intervención administrativa: autorización, comunicación previa y declaración responsable", Revista catalana de dret públic, núm. 42, 2011, pp. 85-114; MELLADO RUIZ, L., "Directiva de servicios y simplificación administrativa: un paso adelante en la racionalización de la organización y actuación administrativas", Noticias de la Unión Europea. Monográfico: La Directiva de Servicios y su transposición al derecho español, núm. 317, junio 2011, pp. 73-86.

${ }^{23}$ El TJCE, Sentencia de 24 de marzo de 2011 Caso Comisión contra España, se ha pronunciado sobre las técnicas autorizatorias en forma de licencia comercial específica previstas en la normativa reguladora del establecimiento de grandes superficies comerciales en el territorio de la Comunidad Autónoma de Cataluña. El TJCE afirma: "Hay que señalar que la normativa controvertida, considerada en su conjunto, instaura un régimen de autorización previa que se aplica a cualquier apertura de un gran establecimiento comercial en el territorio de la Comunidad Autónoma de Cataluña. Ahora bien, en primer lugar, esta normativa limita las zonas disponibles para la implantación de nuevos establecimientos e impone limitaciones a las superficies de venta que pueden autorizarse para éstos. En segundo lugar, dicha normativa únicamente autoriza los nuevos establecimientos si ello no tiene repercusiones en el pequeño comercio existente con anterioridad. En tercer lugar, establece diversas reglas relativas al procedimiento de concesión de la licencia que pueden tener una repercusión negativa real en el número de solicitudes de autorización presentadas o en el número de licencias concedidas. Por consiguiente, la normativa controvertida, considerada en su conjunto, tiene como efecto obstaculizar y hacer menos atractivo el ejercicio, por parte de operadores económicos de otros Estados miembros, de sus actividades en el territorio de la Comunidad Autónoma de Cataluña mediante un establecimiento permanente, afectando de ese modo a su establecimiento en el mercado español. El Reino de España admite, además, que dicha normativa implica determinadas restricciones a la libertad de establecimiento. Por lo tanto, procede declarar que la normativa controvertida, considerada en su conjunto, constituye una restricción a la libertad de establecimiento en el sentido del artículo 43". Sobre este pronunciamiento, FERNÁNDEZ TORRES, J., "La apertura de grandes establecimientos comerciales no puede quedar sujeta a consideraciones económicas (comentario a la STJUE de 24 de marzo de 2011, Comisión c. España, as. C-400/08)", Revista Aranzadi de Urbanismo y Edificación, núm. 23, 2011. 
dible examen del cumplimiento de los requisitos exigidos para cada actividad, también es un instrumento de contacto entre la Administración y el sector privado; una fórmula para recabar las sugerencias del sector servicios, y de trasladar a los operadores en este ámbito las medidas que pueden adoptar para avanzar en la protección del medio ambiente, más allá de los mínimos exigidos en el marco regulador.

Este intercambio de información se extiende de forma natural hacia el consumidor, desde su doble perspectiva de cliente del servicio y ciudadano. La protección de los consumidores como fin esencial de la Directiva de Servicios se convierte en un instrumento más para el control de la calidad y el respeto de los principios exigidos a los responsables de cualquier actividad. La "inspección y vigilancia" de carácter particular que llevan a cabo los consumidores puede completar la labor realizada por la Administración, pero exige de una formación del ciudadano para la protección del medio ambiente; en definitiva, concienciación sobre el respeto a los recursos naturales y al entorno.

\section{El nuevo marco regulador de la Comunidad Autónoma de An- dalucía}

$\mathrm{El}$ articulado de la nueva regulación andaluza sobre parques naturales se encuentra condicionado por tres hitos principales: la crisis económica, la referida transposición de la Directiva de servicios y la nueva concepción de la protección del medio ambiente.

A) En el año 2008 la Comunidad Autónoma de Andalucía elaboró dos disposiciones destinadas a "contribuir a impulsar la actividad económica para paliar los efectos de la actual situación de desaceleración que atraviesa la economía", el Decreto-Ley 1/2008, de 3 de junio, de medidas tributarias y financieras de impulso a la actividad económica de Andalucía y la Ley 1/2008, de 27 de noviembre, de medidas tributarias y financieras de impulso a la actividad económica de Andalucía, y de agilización de procedimientos administrativos.

La Ley 1/2008 incluyó un nuevo precepto en la Ley 2/1989, de 18 de julio, por la que se aprueba el Inventario de Espacios Naturales Protegidos de Andalucía y se establecen medidas adicionales para su protección; mediante esta norma se faculta a los instrumentos de planificación y las normas declarativas de los espacios naturales protegidos para excepcionar del régimen de autorización aquellas actuaciones que no pongan en peligro los valores objeto de protección, estableciendo en cada caso las condiciones en que podrán realizarse. En su Exposición de Motivos se reconocen como significativas las "medidas 
que tienen por finalidad excepcionar determinadas actividades del régimen de autorización, o sustituir la misma por otros sistemas de seguimiento, para impulsar la economía, sin merma de las garantías para la conservación de los valores naturales" 24 .

B) La Comunidad Autónoma de Andalucía adoptó la Ley 3/2010, de 21 de mayo, por la que se modifican diversas leyes para la transposición en Andalucía de la Directiva 2006/123/CE, de 12 de diciembre de 2006, del Parlamento Europeo y del Consejo, relativa a los servicios en el mercado interior. A través de esta norma una vez más se modifica la Ley 2/1989, incluyendo nuevas referencias en el régimen sancionador, a la vista de las nuevas previsiones alternativas a las autorizaciones. De esta forma se añaden al catálogo de infracciones graves la realización de una actuación o actividad sin cumplir los requisitos exigidos o sin haber realizado la comunicación o declaración responsable, así como la inexactitud, falsedad u omisión, de carácter esencial, en cualquier dato, manifestación o documento, que se acompañe o incorpore a la declaración responsable o comunicación previa; y por último, también se considera infracción grave la alteración o el incumplimiento de las previsiones contenidas en la comunicación o declaración responsable para el ejercicio de actividad, o de las propias condiciones impuestas por la administración.

A pesar de las modificaciones aprobadas, el legislador andaluz no ha introducido reformas en la Ley andaluza de Gestión Integrada de la Calidad Ambiental para su adaptación plena al nuevo marco regulador de los Servicios; aún cuando esta norma es básica y regula los instrumentos de control previo para el acceso a buena parte de las actividades con incidencia en el medio ambiente. En concreto en esta norma se regulan la autorización ambiental unificada y la integrada, la evaluación ambiental de planes y programas, la calificación ambiental y las autorizaciones de control de la contaminación ambiental ${ }^{25}$.

\footnotetext{
${ }^{24}$ Esta norma también modifica otras disposiciones autonómicas para exceptuar del régimen de autorizaciones algunas actividades. En este sentido se pueden mencionar la modificación de la Ley 2/1992, de 15 de junio, Forestal de Andalucía, y de la Ley 12/1984, de 19 de octubre, de declaración de las Marismas del Odiel como Paraje Natural y de la Isla de Enmedio y la Marisma del Burro como Reservas Integrales, disposiciones finales cuarta y séptima respectivamente.

25 Sobre esta materia, CANO MURCIA, A., El nuevo régimen jurídico de las licencias de apertura, Ed. La Ley-El Consultor de los Ayuntamientos y de los Juzgados, Madrid, 2010, pp. 300 y ss. El Consejo de Gobierno de la Junta de Andalucía, en su reunión de 28 de abril de 2008 creó un grupo de trabajo para impulsar la agilización de trámites en la administración autonómica; este grupo presentó con fecha de enero de 2009 el Informe sobre Medidas de simplificación de procedimientos administrativos y agilización de los trámites, documento en el que se insta a simplificar y reunificar los procedimientos de la Ley de Gestión Integrada
} 
Cabe recordar que esta Ley creó una nueva figura para la simplificación de los procedimientos y la agilización de los trámites administrativos: la autorización ambiental unificada. Esta autorización integra en una resolución única la evaluación de impacto ambiental y las distintas autorizaciones y exigencias ambientales que, de acuerdo con la legislación sectorial aplicable en materia de vías pecuarias, forestal, espacios naturales protegidos, residuos, emisiones a la atmósfera, vertidos a aguas litorales y continentales, producción y gestión de residuos y calidad ambiental del suelo, entre otras, el promotor de determinadas actuaciones debe obtener de la Consejería competente en materia de medio ambiente y entidades de derecho público dependientes de la misma, con carácter previo a su ejecución o puesta en marcha. Esta virtualidad para reducir los trámites se ha calificado como "ventanilla única ambiental", y comparte principios con la propia Directiva de Servicios.

C) La protección del medio ambiente ha rebasado los propios límites del sector público, y exige una actuación concertada con el sector privado y la participación social. El grado de concienciación ambiental de la población ha experimentado un crecimiento exponencial en los últimos años. Es importante continuar esta senda y lograr la implicación en la protección directa del ciudadano, exigiendo que los servicios y las actividades en las que actúa como consumidor respetan el medio ambiente y no suponen un riesgo para su conservación $^{26}$.

de la Calidad Ambiental. Sobre las propuestas contenidas en este Informe, REINOSO CARRIEDO, A., "La Directiva de servicios. Dificultades para su transposición", El Consultor de los Ayuntamientos y de los fuzgados, núm. 17, 2009, pp. 2457-2466.

Las últimas disposiciones elaboradas en desarrollo de la Ley de Gestión Integrada de la Calidad Ambiental fueron dictadas en el año 2010 y hacen referencia a: la regulación del distintivo de Calidad Ambiental de la Administración de la Junta de Andalucía (Decreto 22/2010, de 2 de febrero); la Protección de la Calidad del Cielo Nocturno frente a la contaminación lumínica y el establecimiento de medidas de ahorro y eficiencia energética (Reglamento para la Protección de la Calidad del Cielo Nocturno de Andalucía Decreto 357/2010, de 3 de agosto); y la regulación de la autorización ambiental unificada, el régimen de organización y funcionamiento del registro de autorizaciones de actuaciones sometidas a los instrumentos de prevención y control ambiental, de las actividades potencialmente contaminadoras de la atmósfera y de las instalaciones que emiten compuestos orgánicos volátiles, y la modificación del contenido del Anexo I de la Ley 7/2007 (Decreto 356/2010, de 3 de agosto).

${ }^{26}$ Según la última encuesta realizada en la Unión Europea, y publicada el 20 de junio de 2011, el medio ambiente constituye una preocupación personal importante para más del $90 \%$ de los encuestados en cada uno de los Estados miembros. La mayoría de los europeos cree que el uso más eficiente de los recursos naturales y la protección del medio ambiente pueden impulsar el crecimiento económico de la UE; a pesar de la crisis económica, el 89 \% de los europeos cree que debería destinarse más financiación a actividades respetuosas con el medio ambiente. El $81 \%$ de los encuestados apoya una legislación centrada en el medio ambiente a escala de la UE como medio necesario para proteger el medio ambiente. Alrede- 
La propia Ley andaluza de Gestión Integrada de la Calidad Ambiental, señala entre sus principios inspiradores el "principio de responsabilidad compartida de las Administraciones públicas, de las empresas y de la sociedad en general, implicándose activamente y responsabilizándose en la protección del medio ambiente" 27 . Por último no debemos obviar la relación entre los parques naturales y el entorno rural, ya que buena parte de la extensión de los espacios naturales andaluces se localiza en el medio rural, que responde a una idiosincrasia propia. En este sentido conviene recordar las previsiones de la Ley 45/2007, de 13 de diciembre, para el Desarrollo Sostenible del Medio Rural, que sitúa entre sus objetivos mantener y ampliar la base económica del medio rural y de su población, sin olvidar la conservación y recuperación del patrimonio natural y cultural del medio rural como elemento clave para la consecución del desarrollo sostenible ${ }^{28}$. La protección del medio ambiente y del entorno rural a través de la gestión territorial exige la adopción de medidas encaminadas a conservar los recursos naturales y los paisajes de las zonas rurales, a la vez que se impulsa su desarrollo económico.

dor del $60 \%$ de los europeos cree que unos procedimientos de contratación pública respetuosos con el medio ambiente constituyen el medio más eficaz para tratar los problemas del medio ambiente, con menos del $30 \%$ que se inclina por soluciones que sean meramente rentables. Los datos sobre esta encuesta se pueden consultar en: http://ec.europa.eu/environment/working_en.htm

${ }^{27}$ En este sentido se han pronunciado las conclusiones del Seminario Internacional celebrado en abril de 2010 bajo el título El Desafio de la Gestión de los Espacios Naturales de Andalucía en un mundo cambiante. Una cuestión de valores. En las conclusiones de la mesa que analizó la dimensión socioeconómica en la gestión de los espacios naturales, se afirma: "Hay que incoporar de una manera más activa a la iniciativa privada en la gestión del patrimonio natural, tanto público como privada. Deben crearse e incrementarse los mecanismos de incentivo y de compensación hacia la iniciativa privada, que propicie una mayor participación de ésta en la gestión de los espacios naturales".

${ }^{28}$ Como se afirma en la Exposición de Motivos: "La Ley pretende contribuir a que los ciudadanos que habitan en municipios rurales puedan dar un nuevo salto cualitativo en su nivel de desarrollo, y a que el inmenso territorio rural y una buena parte de la población del país puedan obtener las mejoras suficientes y duraderas que necesitan. Todo ello en un nuevo contexto histórico, influido por una realidad posindustrial y globalizada, que genera nuevos riesgos pero también nuevos retos y oportunidades para el medio rural. Esta es una Ley de fomento de un desarrollo sostenible del medio rural, que persigue promover acciones públicas e incentivar iniciativas privadas de desarrollo rural para el logro simultáneo de objetivos económicos, sociales y medioambientales. El futuro del medio rural necesita un modelo de desarrollo sostenible". La Ley 45/2007, de 13 de diciembre, para el Desarrollo Sostenible del Medio Rural se completa con la Ley Orgánica 16/2007, de 13 de diciembre. Estas dos disposiciones fueron publicadas en el BOE núm. 299, de 14 de diciembre de 2007, y entraron en vigor el 3 de enero de 2008. 


\section{EL DECRETO 15/2011 SOBRE LOS PARQUES NATURALES ANDALUCES}

\section{Finalidad}

El artículo primero del Decreto 15/2011 afirma que el objeto de esta norma es "establecer el régimen general de la planificación de los usos y actividades en el ámbito territorial de los parques naturales, con la finalidad de consolidar un marco común que garantice la coherencia y homogeneidad en la gestión de los mismos y, a su vez, permita simplificar y agilizar los procedimientos administrativos referidos a la autorización o comunicación de dichos usos y actividades". Por tanto dos ideas principales: establecimiento de un régimen común y simplificación de procedimientos.

Si nos remitimos a la Exposición de Motivos encontramos la motivación última para su elaboración: dinamizar de forma compatible con la conservación de la naturaleza las actividades económicas y sociales que se desarrollan en los espacios naturales. En definitiva, el motor para introducir estas modificaciones es alcanzar la gestión eficaz y sostenible de los espacios naturales. Este principio debe quedar claro, puesto que se encuentra en el origen de cada una de las decisiones adoptadas por las autoridades andaluzas. Si analizamos esta finalidad a la vista del contexto normativo ya comentado, podemos observar que responde a las demandas del momento social y económico que se está viviendo en nuestra Comunidad Autónoma. La clave se encontrará en analizar si todos los intereses en juego se han ponderado de forma adecuada, y si la finalidad última de este Decreto supone la merma de otros principios básicos.

La norma andaluza debe enmarcarse en un escenario más ambicioso a nivel autonómico, que permita dar respuesta a las nuevas demandas de los espacios naturales; el Decreto 15/2011 es el primer paso de una remodelación profunda en el marco regulador de esta materia. En esta línea se está avanzado en nuevos modelos de gestión que propugnan la integración de formas contractuales o de carácter privado, como una posible alternativa ante el incremento de la superficie protegida, la creciente implicación social y el nuevo marco legal ${ }^{29}$.

\footnotetext{
${ }^{29}$ Sobre estos nuevos modelos de gestión, EUROPARC-ESPAÑA, Programa de Trabajo para las áreas protegidas 2009-2013, Ed. FUNGOBE, Madrid, 2009, pp. 31. En este mismo documento se pone de manifiesto la relevancia de los espacios naturales, y expresamente se recoge en pp. 14: "Los espacios protegidos ofrecen servicios a la sociedad tanto de abastecimiento (alimento, agua, madera, recursos genéticos), como de regulación (control de la composición de gases atmosféricos y del clima, regulación del ciclo hidrológico y de las inundaciones, control de la erosión y retención de nutrientes; formación de suelo y ciclos biogeoquímicos; polinización, control biológico de poblaciones, entre otros) y servicios culturales (estéticos, espirituales, educativos y recreativos). Los ecosistemas naturales y seminaturales producen beneficios indispensables para la economía, la salud pública y el bienestar general de los seres humanos".
} 
El contexto socioeconómico y la experiencia acumulada en estos años permiten iniciar una nueva fase que exige una redefinición de los espacios naturales. Disponemos de nuevos datos y de nuevas tecnologías que permiten una concepción más amplia de la conservación y protección, que se traduce en un esquema de gestión actualizado. Como se señala en el "Informe Andalucía +20", elaborado por la Consejería de Medio Ambiente de la Junta de Andalucía, en las dos últimas décadas se ha producido una profunda revolución en la forma de entender los espacios naturales protegidos, que en la actualidad se conciben como instrumentos para garantizar los servicios que proporcionan los ecosistemas junto a la conservación de sus valores patrimoniales ${ }^{30}$.

\section{Estructura y contenido}

La norma andaluza se compone de 34 artículos que se organizan en tres capítulos, y se completa con tres disposiciones adicionales, dos transitorias, una derogatoria, quince disposiciones finales y un anexo.

En lo que respecta a las disposiciones generales, cabe destacar que el régimen jurídico previsto en el Decreto tiene la consideración de normativa de planificación para la ordenación de los recursos naturales. Por tanto, la planificación de la ordenación de los recursos naturales de los parques andaluces se integra por el Plan de Ordenación de los Recursos Naturales (PORN) de cada parque y el Decreto 15/2011.

Los PORN y los Planes Rectores de Usos y Gestión (PRUG) de cada parque prevalecen sobre el Decreto en las siguientes materias: prohibiciones, limitaciones y condiciones específicas que estén establecidas de manera particular para las zonas de reserva, de regulación especial y de regulación común. En consecuencia, los PORN serán competentes para zonificar el parque y determinar los usos permitidos en cada zona, vinculando y prevaleciendo sobre la planificación urbanística. Mientras que el Decreto 15/2011 prevalece sobre las normas generales previstas en los PORN y PRUG.

Con el fin de estructurar este estudio de forma sistemática se ha optado por identificar los aspectos más significativos y analizarlos a lo largo de todo el Decreto.

${ }^{30}$ CONSEJERÍA DE MEDIO AMBIENTE DE LA JUNTA DE ANDALUGÍA, AN + 20. El desafio de la gestión de los Espacios Naturales de Andalucía en un mundo cambiante. Una cuestión de valores, Junta de Andalucía, Sevilla, 2010, p. 43. Documento disponible en: http://www.juntadeandalucia.es/medioambiente/ 


\section{A) Autorizaciones:}

El régimen general previsto en el Decreto andaluz es la exigencia de autorización de la Consejería de Medio Ambiente para cualquier nueva actuación en suelo no urbanizable a realizar en un parque natural. No obstante, se excepcionan aquellos actuaciones que no pongan en peligro los valores objeto de protección del espacio y que cumplan las condiciones establecidas en el Decreto; en estos supuestos las actividades podrán ser de libre realización, o bien estar sometidas a comunicación previa. Estas disposiciones generales deben completarse con la legislación específica y sus propios procedimientos ${ }^{31}$.

El procedimiento para la resolución de las autorizaciones se rige por las previsiones generales previstas en la regulación estatal y autonómica, y por aquellas referencias específicas incorporadas en el propio Decreto. Los principios tradicionales de celeridad, simplificación, buena administración e impulso de oficio son recordados en el texto de la norma andaluza; probablemente con la finalidad de hacer hincapié en la voluntad de esta norma de simplificar y agilizar el procedimiento aplicable. En este mismo sentido destacan las continuas menciones a la presentación por medios telemáticos de los documentos y solicitudes exigidos; así como a la propia sustitución de la documentación necesaria por una declaración responsable, en la que el interesado manifieste que cumple los requisitos, dispone de la documentación acreditativa y se compromete a mantener su cumplimiento.

El procedimiento propiamente dicho se gestiona ante la Delegación Provincial de la Consejería de Medio Ambiente, o bien ante la Dirección General competente en materia de espacios naturales cuando se exceda el ámbito provincial; estos serán los órganos a los que se dirija la solicitud de autorización, y los responsables de su instrucción y resolución. El plazo máximo para dictar resolución es de dos meses y el sentido del silencio será positivo, a excepción de la adquisición de facultades contrarias a las normas reguladoras de los parques naturales o que transfieran al solicitante facultades relativas al dominio público o al servicio público ${ }^{32}$.

31 Art. 4.

${ }^{32}$ Arts. 26 y ss. La disposición adicional primera especifica que todas las previsiones sobre procedimientos, incluidas en el capítulo III, serán de aplicación a los Parques Nacionales de Doñana y Sierra Nevada, y que corresponderá al equipo de gestión de los Espacios Naturales de Doñana y Sierra Nevada el ejercicio de las competencias en materia de autorizaciones, comunicaciones previas e informes preceptivos. 
El Decreto incorpora una serie de actividades, incluidas en el Anexo, que se instruirán y resolverán por un procedimiento abreviado, donde el plazo máximo se reduce a quince días y el sentido del silencio también será positivo, con idénticas excepciones a las analizadas anteriormente. La propia naturaleza de las actividades es la que condiciona la aplicación de un procedimiento abreviado, el Anexo incluye la celebración de eventos deportivos de pesca marítima, actividades como cicloturismo o kitesurf cuando se realicen en espacios donde existan limitaciones de acceso o de uso, etc.

La autorización está sujeta a caducidad, por lo que las actuaciones deben iniciarse en el plazo máximo de dos años; el inicio de la actividad debe comunicarse al órgano que ha concedido la autorización. También es una autorización limitada temporalmente, puesto que el Decreto establece un plazo máximo de cinco años de validez de la autorización para la realización de las actividades. Esta regla general encuentra su excepción en las actividades de uso público, turismo activo y ecoturismo ${ }^{33}$.

El Decreto andaluz sobre parques naturales regula tres modelos de procedimientos excepcionales, que complementan las previsiones sobre el procedimiento general aplicable a las autorizaciones. En lo que respecta a las actuaciones con posible afección a la Red Ecológica Europea Natura $2000^{34}$, la norma andaluza establece una serie de peculiaridades para los supuestos que necesitan autorización ambiental unificada ${ }^{35}$. El interesado también debe aportar memoria explicativa de carácter ambiental, y será el titular de la Delegación Provincial o de la Dirección General quien decida si la actuación debe o no ser sometida a autorización ambiental unificada; en el primer caso la autorización prevista en el Decreto 15/2011 se integrará en la autorización ambiental unificada. Cuando transcurra un plazo de dos meses, el silencio administrativo debe ser interpretado en el sentido de que la actuación no queda sometida a autorización ambiental unificada.

\footnotetext{
${ }^{33}$ Secc. $3^{\text {a }}$, Capítulo II del Decreto.

${ }^{34}$ La Red Ecológica Europea Natura 2000 es una red de espacios naturales protegidos a escala de la Unión Europea, establecida con arreglo a la Directiva sobre hábitats de 1992 y la Directiva sobre aves de 1979. Su finalidad es garantizar la supervivencia a largo plazo de las especies y hábitats europeos más valiosos y amenazados. Más información sobre esta Red en la página web: http://ec.europa.eu/environment/nature/natura2000/index_en.htm

${ }^{35}$ Art. 27.1 d) de la Ley 7/2007, de 9 de julio, y los arts. 2 y 8 del Decreto 356/2010, de 3 de agosto, por el que se regula la autorización ambiental unificada, se establece el régimen de organización y funcionamiento del registro de autorizaciones de actuaciones sometidas a los instrumentos de prevención y control ambiental, de las actividades potencialmente contaminadoras de la atmósfera y de las instalaciones que emiten compuestos orgánicos volátiles, y se modifica el contenido del Anexo I de la Ley 7/2007, de 9 de julio.
} 
Un segundo grupo serían las actuaciones sujetas a autorización o licencia urbanística. En el mismo acto de solicitud de la autorización o licencia urbanística se acompañará la documentación exigida para la autorización regulada en el Decreto 15/2011. El Ayuntamiento deberá dar traslado a la autoridad competente, junto con un informe en el que se pronuncie sobre la compatibilidad de la actuación con el planeamiento urbanístico. La Delegación Provincial o, en su caso, la Dirección General elaborarán un informe vinculante, cuyas condiciones deben ser incluidas en la autorización o licencia urbanística. Por tanto, el pronunciamiento sobre la autorización del Decreto es previa y vinculante a la concesión de la autorización o licencia urbanística; mientras que en los supuestos de comunicación previa previstos en la norma andaluza deberá presentarse a posteriori, una vez concedida la autorización o licencia urbanística.

Y por último se establecen una serie de previsiones específicas para las actuaciones que requieren autorizaciones ambientales de carácter sectorial o impliquen la ocupación de bienes de la Comunidad Autónoma. El Decreto andaluz opta por la unificación de procedimientos, garantizando el respeto de sus previsiones al incluir un informe vinculante elaborado por la Delegación provincial o la Dirección General.

\section{B) Comunicación previa:}

La Delegación Provincial de la Consejería con competencias en medio ambiente o la Dirección General correspondiente serán los órganos competentes ante los que deben presentarse las comunicaciones previas. El Decreto andaluz establece un plazo mínimo de quince días antes de la fecha de inicio de la actuación para presentar la comunicación previa. Con el fin de facilitar este trámite la propia norma dedica un precepto a la presentación por medios electrónicos, donde se remite a la regulación del Registro Telemático Único.

\section{Clasificación de actividades}

El Capítulo II del Decreto se dedica a la clasificación de las actividades que pueden realizarse en los parques naturales, distinguiendo aquellas que necesitan autorización, las que simplemente requieren comunicación previa y las de libre realización; la norma andaluza ha optado por una agrupación por materias.

Si tomamos como referencia las previsiones del Estatuto de Autonomía de Andalucía, se establece la obligación a los poderes públicos de orientar sus po- 
líticas especialmente al desarrollo de la agricultura ecológica, el turismo sostenible, la protección del litoral y la red de espacios naturales protegidos, así como al fomento de una tecnología eficiente y limpia; además de impulsar las políticas y disponer los instrumentos adecuados para hacer compatible la actividad económica con la óptima calidad ambiental, velando porque los sectores productivos protejan de forma efectiva el medio ambiente ${ }^{36}$. Siguiendo estas previsiones hemos optado por establecer cuatro grandes bloques de actividades:

\section{A) Actividades agrarias, forestales y pesqueras}

Los espacios naturales se encuentran condicionados por la relación entre el ser humano y la naturaleza, y las explotaciones tradicionales vinculadas a los sectores agrícola, forestal y pesquero forman parte del propio paisaje de estos entornos. En numerosas ocasiones ha sido la propia huella de estas actividades las que ha condicionado la forma actual de estos entornos naturales. Las técnicas tradicionales para la explotación de estos recursos suponían un impacto soportable por parte de los ecosistemas; sin embargo, el cambio acelerado que se está produciendo con la implantación de nuevos sistemas de explotación de los recursos y la presión que se ejerce sobre estos entornos está alterando el equilibrio entre los espacios naturales y la injerencia humana.

Desde la segunda mitad del siglo pasado se está produciendo un trasvase continuo de población desde las zonas rurales del interior hacia el litoral. La presión demográfica y la fuerte demanda de recursos ha ocasionado la pérdida de especies autóctonas y ocasionado una merma considerable en las reservas pesqueras de nuestras aguas. Por otro lado, las nuevas tendencias en el sector de la agricultura han desembocado en el abandono progresivo de los cultivos tradicionales en algunos territorios y en el desarrollo de cultivos intensivos que presentan nuevos desafios para el entorno en el que se realizan. Este panorama se acrecienta en los espacios naturales protegidos, ya que su singularidad y su principal valor ambiental se encuentran en numerosas ocasiones vinculados a la pervivencia de especies especialmente sensibles a las alteraciones del entorno o a paisajes muy condicionados por la citada sobreexplotación.

En el ámbito agrícola, el Decreto exige la autorización para aquellas actuaciones que pueden incidir sobre las especies del parque, en concreto las explotaciones agrícolas intensivas, los regadíos, la eliminación de setos vivos, la forestación de terrenos agrícolas y los tratamientos fitosanitarios aéreos en terre-

\footnotetext{
36 Art. 197 del Estatuto de Autonomía de Andalucía, LO 2/2007, de 19 de marzo.
} 
nos forestales. Este precepto también incluye una serie de criterios que deben ser respetados en los desbroces y rozas de matorral en terrenos forestales; que se completan con dos principios básicos: las actividades agrarias deben realizarse de forma que se eviten los procesos erosivos y en ningún caso se autorizará la quema de vegetación para obtener nuevos pastos. Esta regulación no se limita a enumerar las actividades sujetas a autorización sino que también establece el modelo a seguir por las actividades agrarias en los parques naturales.

La comunicación previa será de aplicación para la forestación de terrenos agrícolas con especies autóctonas, las podas, los tratamiento fitosanitarios no aéreos en terrenos forestales y el desarraigo de cultivos leñosos; para ésta última práctica se establecen una serie de requisitos adicionales para evitar la erosión del terreno.

Las actividades forestales no se encuentran incluidas en el texto de la norma, pero en la disposición final segunda se incluye una importante modificación del Reglamento Forestal de Andalucía, aprobado por Decreto 208/1997, de 9 de septiembre; por ello, se ha optado por incorporar un apartado específico dedicado a las actividades forestales y a las novedades introducidas en este ámbito con la nueva regulación de las autorizaciones y las comunicaciones previas.

Las modificaciones del Reglamento Forestal comprenden una serie de previsiones idénticas a las ya analizadas del Decreto 15/2011 y que hacen referencia al régimen general de las autorizaciones y comunicaciones previas: procedimiento a seguir, plazos, sentido del silencio, órganos competentes, etc ${ }^{37}$. Se incluyen previsiones específicas vinculadas a las actividades forestales, en este sentido se prevé que las solicitudes de autorización de aprovechamientos incluyan el tipo de aprovechamiento, su cuantía, localización exacta, duración y características; en las solicitudes relativas a usos y aprovechamientos en áreas quemadas también se debe acreditar el cumplimiento de las condiciones impuestas para la restauración de la zona. La norma andaluza establece una regulación transitoria, y remite a la obtención de la autorización a todas las actividades sometidas a comunicación mientras no se aprueben por la Consejería competente las condiciones técnicas para la ejecución de usos y aprovechamientos sometidos a régimen de comunicación previa ${ }^{38}$. En la misma línea de la regulación del Decreto 15/2011, también se incorpora un nuevo precepto al

\footnotetext{
${ }^{37}$ Modificación del art. 97 del Reglamento Forestal de Andalucía.

38 Disposición transitoria segunda y disposición final tercera del Reglamento Forestal de Andalucía.
} 
Reglamento Forestal en el que se hace referencia a las actuaciones con posible afección a la Red Ecológica Europea Natura $2000^{39}$.

La modificación del artículo 96 del Reglamento Forestal de Andalucía establece la relación de actividades sometidas a autorización y a comunicación previa. También se hace referencia a los procedimientos abreviados, cuya concreción se remite a decisión del Consejero competente, sin perjuicio de la referencia a dos actuaciones que en todo caso se someterán a este régimen por la urgencia con la que deben ser adoptadas: la corta o poda de árboles con riesgo de caída o daño sobre edificaciones o infraestructuras y las fitosanitarias, excepto especies catalogadas con algún grado de amenaza.

La regulación de las autorizaciones se concreta con un conjunto de previsiones que completan el marco normativo; se hace referencia al plazo de vigencia que será de un año salvo previsión expresa, y se establece una remisión genérica a Orden de la Consejería competente para aprobar las condiciones técnicas generales de ejecución de las actuaciones. Asimismo, se exige que estén suscritos por técnico competente los planes, programas o proyectos que acompañen a las solicitudes ${ }^{40}$.

\footnotetext{
${ }^{39}$ Art. 97 bis del Reglamento Forestal de Andalucía.

40 i) Usos y aprovechamientos sometidos a autorización: a) Corta de especies principales que constituyan masas arboladas o de matorrales que modifique las condiciones iniciales de la masa. Cuando el objetivo de la corta sea la sustitución de las especies referidas en el párrafo anterior y siempre que no esté recogida en documento de gestión forestal aprobado por la Consejería competente en materia de medio ambiente (proyecto o plan técnico de ordenación de montes, etc.), se presentará solicitud de cambio de uso o plan de repoblación, en función del uso futuro que se pretenda dar al terreno. En el caso de tratarse de la última corta de especies de crecimiento rápido se debe solicitar simultáneamente el destoconado y presentar el plan de repoblación o solicitud de cambio de uso según corresponda; b) Clareos y claras de arbolado con un diámetro normal medio inferior a 20 centímetros, en una superficie superior a 10 hectáreas; c) Desbornizado y primer descorche de masas de alcornocal jóvenes; d) Cualquier actuación en áreas incendiadas; e) Repoblaciones forestales en general, salvo los casos expuestos en el apartado 5.g) y h) [Estos apartados hacen referencia a densificaciones de dehesas o montes huecos con la misma especie o especies principales preexistentes y a la reposición de marras en repoblaciones precedentes]; f) Limpieza de ruedos y veredas, previos al descorche de monte alcornocal, en una superficie de actuación mayor de 50 hectáreas; g) Eliminación de la parte aérea de vegetación arbustiva mediante desbroce con fines de mejora silvícola, prevención de incendios o mejora de pastizales, no incluidas en el apartado 5.i) [Eliminación de la parte aérea de vegetación arbustiva mediante desbroce con fines de mejora silvícola, prevención de incendios o mejora de pastizales, sin que puedan suponer cambio de uso, realizados manualmente o, cuando se emplee maquinaria, en terrenos con una pendiente media inferior al 15\% no se produzca remoción del terreno. El intervalo entre dos desbroces consecutivos será superior a 5 años]. ii) i) Usos y aprovechamientos sometidos a comunicación previa: a) Clareos y claras de arbolado con un diámetro normal medio inferior a 20 centímetros, en una superficie máxima de 10 hectáreas; b) Cortas no sometidas a autorización; c) Descorches a partir del segundo y sucesivos; d) Poda de arbolado o matorral de porte arbóreo tan-
} 
En lo que respecta a las actividades de pesca marítima, marisqueo y acuicultura marina, todas las reseñadas en la norma se encuentran sometidas a autorización; se incluyen en este apartado las instalaciones para el establecimiento de cultivos marinos, la introducción de nuevos elementos, la introducción, traslado o suelta de especies autóctonas en aguas interiores y la celebración de eventos de pesca marítima recreativa. Estas iniciativas deben integrarse en un esquema de protección más amplio, formando parte de una política pesquera y acuícola que incluya previsiones específicas para la implantación y desarrollo de modelos de producción sostenibles adaptados a las condiciones de los ecosistemas protegidos ${ }^{41}$.

\section{B) Actividades turísticas}

En primer lugar hay que analizar cuál es el impacto del turismo sobre los espacios naturales, como ha reconocido el Parlamento Europeo existen pruebas más que suficientes que demuestran el daño que ha causado, y que aún hoy sigue ocasionando, sobre el patrimonio natural; puesto que los espacios naturales españoles reciben cerca de 36 millones de visitas cada $a n ̃ o{ }^{42}$. La única vía es una gestión cuidadosa, que aprenda de las experiencias en este ámbito y minimice las consecuencias sobre el entorno ${ }^{43}$. El modelo a seguir puede venir marcado por algunos ejemplos en los que se ha optado por cerrar la mayor

to de formación como de fructificación, incluida la eliminación de chupones; e) Resalveo de quercíneas y otras especies que se pre- sentan en forma de matas (clareo y poda de pies reservados), hasta una superficie de 10 hectáreas; f) Aprovechamiento de piña; g) Densificaciones de dehesas o montes huecos con la misma especie o especies principales preexistentes; h) Reposición de marras en repoblaciones precedentes; i) Eliminación de la parte aérea de vegetación arbustiva mediante desbroce con fines de mejora silvícola, prevención de incendios o mejora de pastizales, sin que puedan suponer cambio de uso, realizados manualmente o, cuando se emplee maquinaria, en terrenos con una pendiente media inferior al $15 \%$ no se produzca remoción del terreno. El intervalo entre dos desbroces consecutivos será superior a 5 años; j) Limpieza de ruedos y veredas, previos al descorche de monte alcornocal, hasta una superficie de actuación de 50 hectáreas; k) La norma incluye una cláusula genérica que remite a la comunicación previa a todas aquellas actividades sujetas a autorización que estén previstas bien en un plan técnico o proyecto de ordenación aprobado, bien en un plan de prevención de incendios.

${ }^{41}$ CONSEJERÍA DE MEDIO AMBIENTE DE LA JUNTA DE ANDALUCÍA, $A \mathcal{N}+20$. op. cit., pp. 76 y 77.

${ }^{42}$ EUROPARC-ESPAÑA, op. cit., pp. 13.

${ }^{43}$ Uno de los ejemplos de los daños a los espacios naturales como consecuencia de la presencia de un número elevado de visitantes es el caso del río Chíllar en Nerja (Málaga). Sobre este asunto cabe remirtirse al artículo elaborado por CABEZAS, E., y publicado en la versión digital del Diario Sur, con fecha de 27 de junio de 2011, bajo el título "La Junta estudia fórmulas para frenar la masificación en el río Chíllar de Nerja", que recogía la siguiente información: "El paraje natural de Los Cahorros del río Chíllar, en Nerja, enclavado en pleno corazón de la Sierra Almijara, se ha convertido, por su extraordinaria belleza 
parte de del espacio natural y se dedica una parte acotada a un turismo sostenible de alto nivel, que permite dar a conocer el entorno y supone un impulso económico para las localidades vecinas ${ }^{44}$.

La regla general por la que opta el Decreto es la libre realización; a diferencia de los grupos anteriores, para esta materia se especifica que estas actividades no estarán sujetas a autorización ni comunicación previa siempre que se realicen en los lugares, fechas y condiciones sin limitación de acceso o de uso, y que no tengan repercusiones negativas sobre el medio natural, no se alteren las infraestructuras ni los equipamiento, ni se impida su disfrute por otros ciudadanos ${ }^{45}$. No podemos olvidar que el turismo también constituye un elemento que potencia la conservación y el desarrollo de los espacios naturales, puesto que se configura como un incentivo para las localidades vecinas que vinculan el auge del sector turístico al entorno natural en el que se ubican ${ }^{46}$; ésta ha sido la apuesta de la Comunidad Autónoma para potenciar la libre realización de las actividades, integrando explotación y conservación.

y abundancia de agua, en un lugar muy frecuentado por los senderistas, especialmente en los meses estivales, desde hace unos años para acá. Esta situación ha provocado graves problemas de masificación en el entorno, que han desembocado en la presencia de abundantes basuras, así como daños en el patrimonio natural, con pintadas y grafitis en las paredes de piedra que dan nombre a este enclave único". Información disponible en el enlace: http://www.diariosur.es/v/20110627/axarquia/junta-estudia-formulas-para-20110627.html

44 PARLAMENTO EUROPEO, Resolución de 3 de febrero de 2009, sobre los espacios naturales en Europa (2008/2210(INI)), apartado $9^{\circ}$ (DOUE, C 67, de 18 de marzo de 2010, pp. 1-4).

${ }^{45}$ En virtud de lo dispuesto en el art. 3 del Decreto, son actividades de uso público "aquellas relacionadas con la cultura y la educación, el ocio y el turismo y que tienen como finalidad acercar a los visitantes a los valores naturales y culturales del espacio protegido de que se trate. No se integran en dichas actividades las realizadas por los particulares para la explotación de los recursos primarios de las fincas que posean por cualquier título"; tienen la consideración de actividades de turismo activo "las relacionadas en el Anexo V del Decreto 20/2002, de 29 de enero, de turismo en el medio rural y turismo activo, conforme a la definición dada por el artículo 4 del mismo Decreto"; y son definidas como actividades de ecoturismo "aquellas que se determinen mediante Orden conjunta de las personas titulares de las Consejerías competentes en materia de turismo y medio ambiente, prestadas bajo criterios de responsabilidad ambiental y que estén basadas en distintas formas de percepción directa de los recursos patrimoniales del territorio, ya sean naturales o culturales tales como el aprecio, disfrute, sensibilización, interpretación de los recursos o turismo ecológico".

${ }^{46}$ En este sentido se ha pronunciado la Agenda para un turismo europeo y sostenible, elaborada por la Comisión y en la que se señala: "El reto consistirá en encontrar un equilibrio adecuado entre el desarrollo autónomo de los destinos y la protección de su medio ambiente por un lado y el desarrollo de una actividad económica competitiva, por otro. Sin embargo, el trabajo del Grupo para la Sostenibilidad del Turismo ha confirmado que, más que cualquier otra actividad económica, el turismo puede desarrollar sinergias por medio de una intensa interacción entre el entorno y la sociedad. Esto se debe a que el desarrollo de destinos turísticos está estrechamente relacionado con su entorno natural, sus especificidades culturales, su 
Estas propuestas se relacionan con las directrices del Plan General del Turismo Sostenible de Andalucía 2008-2011, que incorpora una orientación estratégica encaminada al fomento del "desarrollo basado en la diferencia a partir del reforzamiento de la identidad del espacio turístico basada en el patrimonio natural, cultural y paisajístico"47. En este Plan se incide en la diferenciación, la posibilidad de elaborar experiencias singulares, no sustituibles, como modelo para impulsar el sector turístico. En esta línea se presentan distintos escenarios de actuación, en los que destaca el apartado dedicado al turismo rural y de naturaleza. Las actividades realizadas en un parque natural andaluz constituyen uno de los ejemplos más significativos de experiencia única por el entorno en el que se realizan; sin embargo, la experiencia que se ha acumulado en la dilatada trayectoria turística de nuestra Comunidad Autónoma debe servir de referente a la hora de ofrecer un turismo de calidad en los parques naturales. En nuestro territorio, los abusos han ocasionado la pérdida irreparable de numerosos paisajes de gran belleza, en especial en la zona del litoral andaluz.

En este contexto, y sin perjuicio de esta regulación genérica y del principio de libre realización de las actividades, la conservación de los valores naturales que motivaron la declaración del parque natural constituyen el principal objetivo; por tanto, se faculta al titular de la Consejería competente en materia de medio ambiente para limitar, condicionar o someter a autorización cualquier actividad que ponga en riesgo los citados valores naturales. Esta declaración tendría efectos inmediatos, pero se encontraría limitada temporalmente y tiene un carácter cautelar. Se trata de primar la calidad del espacio turístico, aún cuando esta opción se traduzca en una limitación para el sector.

\footnotetext{
interacción social, su seguridad y el bienestar de las poblaciones locales. Estas características hacen del turismo la fuerza motriz para la conservación y el desarrollo de los destinos, tanto directamente, mediante la sensibilización y el apoyo a sus ingresos, como indirectamente, al facilitar una justificación económica para este apoyo por parte de terceros", COMISIÓN DE LAS COMUNIDADES EUROPEAS, Comunicación de la Comisión "Agenda para un turismo europeo y sostenible", COM (2007) 621 final, Bruselas, 19 de octubre de 2007.

${ }^{47}$ Decreto 261/2007 de 16 de octubre de 2007, por el que se aprueba el Plan General de Turismo Sostenible de Andalucía 2008-2011. En esta misma línea se ha manifestado Europarc-España, considera el fomento de las buenas prácticas turísticas en espacios naturales protegidos y la calidad en la gestión del uso público en espacios protegidos como el objetivo básico, y toma como referencia la consolidación de las iniciativas como la Carta Europea de Turismo Sostenible y la Q de Calidad en uso público. Para alcanzar estos fines se proponen desde Europarc-España las siguientes iniciativas: -Divulgar los avances de los proyectos de la CETS y la Q; - Promover el seguimiento y la asistencia técnica; -Desarrollar la metodología para la implantación de la II Fase de la CETS; -Apoyar a la Red Ibérica de parques con la CETS. EUROPARC-ESPAÑA, op. cit., pp. 30.
} 
Para conocer las limitaciones en el acceso a un parque natural habrá que acudir a la resolución de la Delegación Provincial o de la Dirección General, en función del ámbito territorial afectado. El régimen transitorio previsto en el Decreto 15/201 $1^{48}$ impone la previa obtención de autorización para las actividades de uso público, turismo activo y ecoturismo de libre realización, mientras no se apruebe la resolución sobre limitaciones de acceso o uso incluidos dentro del parque natural, así como las fechas, lugares y condiciones para la realización de las actividades.

Los términos en los que puedan desarrollarse estas actividades y las condiciones necesarias para la seguridad de las personas y la protección y conservación del parque natural se remiten a sendas Órdenes de las Consejerías competentes. El Decreto distingue entre las actividades declaradas de turismo activo y ecoturismo, reguladas por Orden conjunta de las Consejerías competentes en materia de turismo, deporte y medio ambiente; y las actividades de uso público, reguladas por Orden de la consejería con competencias sobre medio ambiente. En virtud de lo previsto en la Ley 8/2003, de 28 de octubre ${ }^{49}$, se faculta a los titulares de las Consejerías competentes para incluir en estas Órdenes la exigencia de fianza o de seguro de responsabilidad civil por daños al medio ambiente, para la realización de actividades organizadas de ocio, deporte o turismo activo o para la realización de grabaciones audiovisuales cuando pudieran afectar a especies silvestres amenazadas.

\footnotetext{
${ }^{48}$ Disposición transitoria primera. En el apartado tercero de la disposición final decimocuarta, se afirma: "Mediante resolución de los órganos directivos indicados en el artículo 10.2 se establecerán, para cada parque natural, los equipamientos públicos, caminos, pistas forestales u otros espacios donde exista alguna limitación de acceso o de uso, así como los lugares, fechas y condiciones para la realización de las actividades relacionadas en los apartados 3 y 6 del Anexo".

${ }^{49} \mathrm{El}$ art. 23 de la Ley 8/2003, de 28 de octubre, de la flora y la fauna silvestres, dispone: "1. Las actividades de ocio, deporte y turismo activo, así como las de carácter tradicional que se desenvuelvan en el medio natural, deberán respetar sus valores medioambientales, especialmente las especies silvestres y sus hábitats, así como las condiciones del paisaje; 2. Los órganos competentes en la materia establecerán las normas y limitaciones que hayan de cumplir dichas actividades, incluida la circulación de vehículos a motor, en la medida en que supongan un riesgo para las especies silvestres o sus hábitats o interfieran en la reproducción u otros procesos biológicos esenciales de aquéllas. Reglamentariamente se regulará el régimen de autorización de este tipo de actividades; 3. Asimismo, se podrá exigir fianza para la concesión de autorizaciones administrativas de realización de actividades organizadas de ocio, deporte o turismo activo o para la realización de grabaciones audiovisuales cuando pudieran afectar a las especies silvestres amenazadas, cuya cuantía se fijará en proporción a la actividad que se pretenda realizar y a las responsabilidades que pudieran derivarse por daños causados; 4. La fianza será devuelta una vez comprobada la correcta ejecución de la actuación autorizada, pudiendo ser reducida conforme a las detracciones necesarias para atender a los daños y responsabilidades producidas".
} 
El Decreto 15/2011 se remite a la normativa específica en materia de turismo activo y turismo en el medio rural para la regulación de las actividades de turismo activo y ecoturismo que se desarrollen por empresas. En lo que respecta a las actividades que requieren autorización pueden clasificarse en: grandes concentraciones de personas, acampadas y campamentos juveniles ${ }^{50}$, actividades de uso público que se realizan fuera de los lugares designados o en espacios con limitaciones, vivaqueo y acampada nocturna de grandes grupos, y actividades de filmación y fotografía con equipos auxiliares.

El Decreto hace referencia a las romerías, fiestas populares, eventos deportivos y otras concentraciones con menos de diez años de antigüedad o en las que se produzcan modificaciones de las condiciones establecidas en la autorización concedida; a las acampadas y campamentos juveniles, y a una serie de actividades diversas incluidas en el anexo y que comprenden desde el senderismo o el cicloturismo en espacios con limitación de acceso o de uso, hasta la acampada nocturna de grupos de más de 15 personas, entre otras.

La regulación sobre autorizaciones incluye un listado de actividades que con carácter general no podrán realizarse. Estas limitaciones responden a la necesidad de limitar estas actividades por razón del lugar de realización o de los medios que implican; especial mención merece la prohibición del estacionamiento para pernoctar de caravanas y autocaravanas fuera de los lugares habilitados a tal fin, porque es una actividad que cada vez cuenta con más adeptos y puede suponer una alteración importante para los entornos protegidos. Estas prohibiciones podrán ser excepcionadas por el titular de la Delegación Provincial o de la Dirección General siempre que estén relacionadas con eventos deportivos, turísticos o culturales; tan sólo se excluyen las actividades recreativas que empleen aeronaves con motor a realizar en zonas de reserva $\mathrm{A}^{51}$.

\footnotetext{
${ }^{50}$ En virtud de lo dispuesto en la disposición final primera del Decreto 15/2011, se modifica el párrafo b) del artículo 2 del Decreto 45/2000, de 31 de enero, sobre organización de acampadas y campamentos juveniles en Andalucía, que queda redactado en los siguientes términos: "b) Acampada juvenil: Se entiende por acampada juvenil la organización de campos de trabajo, marchas, colonias o cualquier actividad de similar naturaleza que tengan un contenido educativo, ecológico, deportivo o recreativo, en la que participen más de diez personas y cuya duración máxima sea de cinco días e impliquen la colocación sobre el terreno de algún tipo de instalación eventual destinada a habitación o el asentamiento en espacios naturales".

51 Según lo previsto en el art. 3, las zonas de reserva (zonas A) son " aquellos espacios que albergan ecosistemas de relevantes valores ecológicos, paisajísticos o científicos que por su singularidad, fragilidad o función, requieren un nivel de conservación y protección especial".
} 
La presentación de comunicación previa se limita a grandes concentraciones de personas, acampadas y campamentos para la realización de actividades de educación ambiental y al vivaqueo y la acampada nocturna vinculados a actividades de travesía de montaña. La norma establece una limitación común a todas estas actividades vinculadas al uso del fuego, que sólo se permite para la preparación de alimentos y en los lugares habilitados.

En el caso de las grandes concentraciones la comunicación previa se ajusta a los supuestos excluidos de la solicitud de autorización, limitándose a las romerías, fiestas populares, eventos deportivos y otras concentraciones con más de diez años de antigüedad sin alteraciones en las condiciones de la autorización original. Las referencias a las acampadas y campamentos comprenden únicamente los dedicados a actividades de educación ambiental, y se incluyen requisitos en cuanto a la recogida de residuos, el número máximo de personas y las zonas para la realización de actividades. También se enumeran requisitos propios para las actividades de vivaqueo y acampada nocturna sobre el número máximo de personas, los lugares de acampada y la recogida de residuos.

Estas prohibiciones y limitaciones inciden en la necesidad de reducir la huella ecológica del desarrollo turístico, desarrollando un modelo turístico que genere empleo de calidad y que proteja los recursos culturales, ambientales y sociales de Andalucía. En definitiva, se está concretando uno de los programas previstos en el Plan de Calidad Turística de Andalucía 2010-2012, que también aboga por la implantación de sistemas de gestión ambiental. La coherencia entre la regulación específica sobre espacios naturales y las disposiciones sobre el sector turístico exigen de una implantación paralela En una Comunidad Autónoma como la andaluza, donde el turismo es un elemento económico estratégico y principio rector de las políticas públicas, y ha sido asumido como una competencia autonómica exclusiva con referencia expresa a la ordenación y planificación del sector turístico, tan sólo cabe elaborar una política sobre espacios naturales coordinada con las iniciativas desarrolladas en este sector ${ }^{52}$.

\section{C) Infraestructuras, instalaciones y construcciones}

Este apartado constituye el núcleo fundamental de las actividades reguladas en el Decreto, ya que se configura como el instrumento para la elaboración del modelo territorial de la Comunidad Autónoma de Andalucía. En primer lugar hay que poner de manifiesto que el contexto de cambio en el que nos encon-

${ }^{52}$ Arts. 37.1.14 y 71 de la LO 2/2007, de 19 de marzo, del Estatuto de Autonomía de Andalucía. 
tramos va a condicionar que los espacios naturales protegidos se alteren de forma significativa en los próximos años; los efectos del cambio climático, con los desajustes en las temperaturas y en los ciclos lluviosos y de sequían afectarán considerablemente a estos ecosistemas. De ahí que deba reforzarse la integración de los espacios naturales protegidos en el conjunto del territorio de la Comunidad Autónoma, puesto que la modificación de los ecosistemas dará lugar a cambios en los límites territoriales de estos espacios que se ampliarán o reducirán.

La visión global del territorio, en el que también se incluyen los espacios naturales protegidos, es el paso previo para la adopción de cualquier medida de planificación y gestión. La integración territorial de estos espacios permite una valoración en conjunto y supera la tendencia a un estudio aislado e individulizado, que identificaba estos espacios con islas protegidas en un mar de espacios ajenos, aún cuando esta concepción era irreal. Los límites de los espacios naturales son fronteras teóricas que no permiten aislar a sus ecosistemas de los efectos de las actividades que se realizan en los espacios vecinos; estas influencias son recíprocas, los flujos se dirigen desde los espacios naturales al resto del territorio y viceversa. La integración territorial de los espacios naturales supone dotar de un marco regulador y planificador a una realidad que supera los límites prefijados de las zonas de protección.

En esta visión global la zonificación de los espacios permite reconocer las actividades y los usos que admite ese territorio. En el caso de los espacios naturales protegidos estas distinciones del territorio permiten establecer una clasificación de los usos y actividades que puede soportar cada una de las zonas clasificadas, con el fin de alcanzar una explotación sostenible de los recursos y de reducir los impactos negativos que puedan inferirse en el entorno. La planificación vinculada a este modelo de distribución por zonas se convierte en el eje para una política global sobre el espacio natural; no se trata de la protección aislada de parcelas de territorio de especial sensibilidad, si no de una visión completa de todo el entorno. Para el desarrollo de estos planes hay que tomar como referencia la propia naturaleza de los espacios naturales, cómo influyen los referente espaciales y temporales; por ejemplo, la dinámica del litoral o de los ríos, las migraciones de las aves o los ciclos de sequía y lluvia.

Las infraestructuras e instalaciones se regulan de nuevo en dos preceptos, el primero de ellos dedicado a las actuaciones sometidas a autorización, y el segundo a las sometidas a comunicación previa. El elenco de actuaciones mencionadas es dispar y abarca desde las infraestructuras de telecomunicaciones, hasta la instalación de oleoductos o los dragados marinos, así hasta un total de 
dieciséis actuaciones en las que se exige la autorización ${ }^{53}$. Asimismo, el precepto dedicado a estas actuaciones sometidas a un régimen más estricto de control enumera un conjunto de condiciones que deben ser respetadas en cualquier circunstancias. Se prohíben los cercados y vallados cinegéticos electrificados; y también las instalaciones aeronáuticas, con excepción de las destinadas a servicios públicos esenciales, urgencias médicas y lucha contra incendios.

También se incluyen una serie de previsiones sobre la gestión de residuos, quedando prohibidas las instalaciones fijas, salvo las previstas en los planes territoriales de gestión de residuos. En el caso de instalaciones móviles, se exige autorización del Delegado Provincial, informe de la junta rectora del parque, cumplimiento del procedimiento que corresponda según el tipo de residuos, e inexistencia de alternativa viable fuera del parque. Asimismo, todas las instalaciones deben ejecutarse pensando en su completa integración en el entorno, salvo que razones de seguridad exijan previsiones específicas.

Con carácter genérico, las actuaciones que precisan comunicación previa están vinculadas a la conservación, mejora y acondicionamiento de carreteras no sometidas a autorización ambiental unificada, caminos cuando concurran una serie de requisitos en el terreno y la construcción no suponga alteración del entorno, las actividades de limpieza de márgenes y dragado de los canales regables, la reposición de cercas o vallados superiores a 20 metros, y las actuaciones sobre infraestructuras que no exijan autorización y tampoco supongan una modificación de sus características ${ }^{54}$.

\footnotetext{
${ }^{53} \mathrm{El}$ art. 14.1 dispone: "Quedan sujetas a la obtención de autorización, conforme al procedimiento regulado en este Decreto, las siguientes actuaciones cuando no estén sometidas a AAI o AAU: a) Construcción de líneas para el transporte o suministro de energía eléctrica; b) Infraestructuras de telecomunicaciones; c) Instalaciones de producción de energía eléctrica solar, termoeléctrica o fotovoltaica, salvo las fotovoltaicas de potencia no superior a 10 Kilovatios que se incluyen en el artículo 15; d) Oleoductos y gasoductos; e) Obras costeras de defensa y protección de la costa y obras marítimas; f) Dragados marinos; g) Instalaciones de desalación o desalobración de agua. h) Espigones y pantalanes no sometidos a AAU y establecimiento de puntos de fondeos de embarcaciones de recreo en aguas marítimas; i) Obras de conservación, acondicionamiento y mejora de caminos, salvo las incluidas en el artículo 15.b); j) Construcción y mejora de instalaciones para la captación y conducción de agua; k) Construcción de instalaciones destinadas a retener agua o almacenarla, tales como abrevaderos, albercas, balsas o depósitos; l) La modificación del trazado, sección o características de las acequias existentes; m) Cualquier actuación en los cauces, en las zonas de servidumbre, las de policía y los perímetros de protección; n) Construcción, instalación o adecuación de infraestructuras vinculadas al desarrollo de actividades de uso público y turísticas; ñ) La instalación de cercas, vallados y cerramientos no cinegéticos no incluidos en el artículo 15.f); o) Los caminos rurales no incluidos en el artículo 15.d)".

54 También exigen comunicación previa las instalaciones de producción de energía eléctrica fotovoltaica no superior a 10 kilovatios, y la apertura de caminos rurales en explotaciones agrarias en activo y la instalación de cercas, vallados y cerramientos no cinegéticos que cumplan una serie de condiciones.
} 
En el ámbito de las construcciones y edificaciones la regla general es la autorización; la comunicación previa se ciñe a dos tipos de actuaciones: las casetas auxiliares para pequeñas instalaciones de servicio de las explotaciones agrícolas, acuícolas y salineras, con determinados requisitos sobre superficie de explotación, superficie construida, altura y caracteres de la cubierta; las obras de conservación, rehabilitación o reforma de edificaciones y construcciones, cuando no haya aumento del volumen edificado y no suponga alteración de las características edificatoras externas o dicha alteración no requiera proyecto técnico de obra.

En este apartado destacan un conjunto de previsiones específicas que merecen un análisis pormenorizado:

1) Parámetros de edificación y características constructivas en suelo no urbanizable: En este ámbito resultan clave las previsiones sobre los instrumentos de planeamiento urbanístico de los municipios y de los Planes de Ordenación de los Recursos Naturales (PORN) y los Planes Rectores de Uso y Gestión (PRUG) de los distintos parques naturales.

Los planes urbanísticos municipales tienen competencia para regular sobre las parcelas mínimas para las edificaciones y construcciones, las distancias mínimas y las características edificatorias externas; además, el planeamiento urbanístico regulará las condiciones para las edificaciones y construcciones de interés público en suelo no urbanizable.

Especial mención merece la regulación sobre la relación entre los PORN y los PRUG y los planes urbanísticos ${ }^{55}$ :

- Los instrumentos de planeamiento urbanístico deben ajustarse a la zonificación y usos del suelo realizadas por el PORN.

- Los planes urbanísticos con informe favorable de valoración ambiental de la Consejería de Medio Ambiente sustituirán a las previsiones urbanísticas relativas a parámetros de edificación y características constructivas contenidas en los PORN y los PRUG.

- Prevalecerán en todo caso las prohibiciones, limitaciones y condiciones específicas previstas en los PORN y los PRUG para las zonas de reserva, de re-

55 Art. 18 y disposición transitoria segunda. 
gulación especial y regulación común, en atención a los valores a proteger y a las características singulares de cada espacio ${ }^{56}$.

Consideramos que este nuevo modelo de planificación basado en la complementariedad de las previsiones urbanística municipales y las disposiciones de los PORN y PRUG se enmarca en las directrices que desde todos los foros se están asumiendo sobre la gestión de los espacios naturales. La apuesta es que el modelo de zonificación debe optar por ser flexible y adaptarse a los condicionantes socioculturales locales.

Esta realidad es un reflejo más de la apuesta por involucrar en la gestión a las localidades en cuyo territorio se ubican los espacios naturales. De ahí que la coordinación interadministrativa adquiere una nueva dimensión gracias a las previsiones del Decreto, la integración de la Administración local como sujeto activo en la toma de decisiones sobre los espacios naturales supone un paso más en el establecimiento de un nuevo modelo de gobernanza ambiental en Andalucía. De esta forma los gobiernos locales dejan de actuar como meros receptores de las políticas sobre planificación y gestión ambiental de su territorio y se convierten en actores con capacidad de decisión sobre su entorno. La implicación del nivel de administración más cercano al ciudadano redundará sin duda en un aplicación más efectiva de las propuestas adoptadas, ya que permitirá recoger las demandas de la población local.

\footnotetext{
${ }^{56}$ La disposición adicional segunda establece: "En el plazo de tres años deberá estar concluido el proceso de revisión de los planes de ordenación de los recursos naturales de los parques naturales de Andalucía, para su adaptación a la normativa general establecida por este Decreto, respetando en todo caso lo dispuesto en el artículo 18.5. Dentro del proceso de revisión del plan de ordenación de los recursos naturales de cada parque natural, se establecerán medidas sobre el conjunto de los mismos que favorezcan la conectividad ecológica entre parques naturales". El Decreto también incluye una disposición derogatoria única en la que se incluyen referencias particulares a la derogación de preceptos de los PORN de los siguientes espacios naturales: Parque Natural Sierra María-Los Vélez, aprobado por Decreto 191/2005, de 6 de septiembre; Frente Litoral Algeciras-Tarifa, aprobado por Decreto 308/2002 de 23 de diciembre; Parque Natural de Sierra Mágina, aprobado por Decreto 57/2004, de 17 de febrero; Parque Natural Sierra de Aracena y Picos de Aroche, aprobado por Decreto 210/2003 de 15 de julio; Parque Natural Montes de Málaga, aprobado por Decreto 187/2003, de 24 de junio. También se modifican preceptos del PORN de los siguientes espacios naturales: Parque Natural de la Sierra de Andújar (disposición final tercera); Parque Natural de la Sierra de Cardeña y Montoro (disposición final cuarta); Frente Litoral Algeciras-Tarifa (disposición final quinta); Parque Natural Montes de Málaga (disposición final sexta); Parque Natural Sierra María-Los Vélez (disposición final séptima); Parque Natural de Doñana (disposición final octava); Parque Natural de la Sierra de las Nieves (disposición final undécima); Parque Natural de la Sierra Subbética (disposición final decimosegunda). Sobre la modificación de los PRUG, se incluyen referencias del Parque Natural Sierra Norte (disposición final novena); Parque Natural de Los Alcornocales (disposición final décima); Parque Natural del Estrecho (disposición final quinta).
} 
Esta participación de la administración local es una plasmación de las propias competencias que en materia de medio ambiente ostenta este nivel administrativo, previstas con carácter genérico en la Ley 7/1985, de 2 de abril, de Bases de Régimen Local, además de en otras disposiciones específicas. Dotar al ámbito local de los instrumentos necesarios para ejercer estas competencias es el resultado de su indispensable participación en la gestión de los espacios naturales protegidos, como expresión máxima de la protección ambiental en un determinado territorio ${ }^{57}$.

En este nuevo contexto coincidimos con las propuestas del "Informe Andalucía +20 " en la necesidad de desarrollar una planificación de la gestión del capital natural en cascada, que integre una jerarquía de objetivos así como los programas de gestión previstos en las disposiciones comunitarias, nacionales, autonómicas, provinciales o municipales ${ }^{58}$. No se trata de reducir la gestión al único control de la administración local, el modelo de gobernanza ambiental requiere la integración de todos los niveles, desde el ámbito internacional al local. Las propuestas de los gobiernos locales deben estar integradas en el esquema para la protección y conservación de los espacios naturales, que no se limita al control autonómico ni estatal, si no que rebasa nuestras fronteras al integrar las previsiones de la Unión Europea y de las disposiciones internacionales.

2) Condiciones generales para la construcción, conservación, rehabilitación o reforma de construcciones y rehabilitaciones: El Decreto incide en la necesidad de minimizar el impacto de la construcción y de las instalaciones o infraestructuras que resulten; con previsiones para la integración de la arquitectura en el paisaje, la restauración de los daños ambientales y proyectos sobre residuos, saneamiento y abastecimiento. También se regulan en detalle los caracteres de las edificaciones rehabilitables, y la preferencia de la rehabilitación frente a la nueva construcción.

3) Nuevas construcciones y sus requisitos, completados por las previsiones de la Ley 7/200259: En este grupo se incluyen las explotaciones agrarias, acuícolas y sa-

${ }^{57}$ En relación a las competencias locales sobre protección del medio ambiente, VERAJURADO, D., "Evolución e integración de la perspectiva ambiental en la legislación y su influencia en el ámbito local", fábega, núm. 91, 2002 (Ejemplar dedicado a: Sostenibilidad y medio ambiente en la provincia de Málaga (II), coord. por Saturnino Moreno Borrell), pp. 75-92.

58 CONSEJERÍA DE MEDIO AMBIENTE DE LA JUNTA DE ANDALUCÍA, $A \mathcal{N}+20$. op. cit., pp. 99.

${ }^{59} \mathrm{El}$ art. 52 de la Ley 7/2002, de 17 de diciembre, de Ordenación Urbanística de Andalucía, regula el régimen del suelo no urbanizable. Sobre la Ley de Ordenación Urbanística de Andalucía, LÓPEZ MENUDO, F., "La Ley de Ordenación Urbanística de Andalucía", Justicia administrativa: Revista de derecho administrativo, 2003, pp. 7-39. 
lineras, acreditando la vinculación de las construcciones con la explotación, incluidas las nuevas edificaciones unifamiliares aisladas. Además de las actuaciones declaradas de interés público de implantación de usos industriales o terciarios vinculados a la producción, la primera transformación o la comercialización de los productos agrarios o análogos. Y por último, las actuaciones promovidas por administraciones públicas para la implantación de infraestructuras, dotaciones y equipamientos, y las construcciones vinculadas a las obras públicas.

4) Edificios para actuaciones declaradas de interés público de implantación de establecimientos turísticos: Como regla general estas edificaciones deben ocupar suelo urbano o urbanizable, sólo cuando estas actuaciones sean declaradas de interés público y previo informe de la junta rectora del parque natural se podrán llevar a cabo en suelo no urbanizable; sin perjuicio de las previsiones específicas sobre turismo, patrimonio histórico y ordenación urbanística que deban ser respetadas ${ }^{60}$. En aplicación de las disposiciones generales, será preferente la rehabilitación o reforma frente a la nueva edificación, y sólo se autorizará un incremento de la superficie construida que no supere el 35\%. El Decreto de nuevo incluye una excepción, autorizando un mayor incremento de superficie construida cuando quede acreditado que "no se vulneran los valores naturales del espacio y que se garantiza el desarrollo sostenible de la actividad"; incluso se permite la autorización de construcciones auxiliares vinculadas a la oferta complementaria de estos establecimientos.

La aplicación de este régimen excepcional exige una valoración previa sobre la sostenibilidad de esta medida. Si tomamos como referencia el concepto de sostenibilidad, debemos tener presente que los ecosistemas afectados no pueden saturarse, es decir, no cabe la sobreexplotación de sus recursos ni se pueden emitir más residuos de los que puedan asumir; asimismo, hay que tener en cuenta el desarrollo social y económico del entorno. Las actuaciones declaradas de interés público están obligadas a cumplir estos requisitos, ninguno de estos tres factores: social, ambiental y económico, puede prevalecer indiscriminadamente, de tal forma que anule a los demás condicionantes. Esta realidad exige una evolución paralela de los intereses en juego; las autoridades competentes son las responsables de velar porque se cumplan estos fines y la sostenibilidad del proyecto quede demostrada desde todas sus perspectivas.

\footnotetext{
${ }^{60}$ Ley 12/1999, de 15 de diciembre, del Turismo; Ley 14/2007, de 26 de noviembre, de Patrimonio Histórico de Andalucía y Ley $7 /$ 2002, de 17 de diciembre, de Ordenación Urbanística de Andalucía.
} 


\section{D) Otras actividades}

El Decreto concluye el capítulo II con un precepto que enumera una serie de actividades sometidas a autorización, cuando no estén sujetas a autorización ambiental integrada o autorización ambiental unificada. Estas actividades incluyen previsiones sobre explotaciones y yacimientos minerales, instalaciones de señales y publicidad, actividades cinematográficas y fotográficas, y difusión de información sobre el parque y sus especies que supongan un riesgo para su conservación. Este apartado se completa con las previsiones incluidas en la disposición adicional tercera, en la que se enumeran un conjunto de actividades sometidas a autorización con carácter específico en determinados parques naturales $^{61}$.

El Decreto regula escuetamente las actividades de investigación, limitándose a exigir la autorización cuando las actividades científicas impliquen el montaje de infraestructuras; así como en aquellos supuestos en los que la difusión de la información originada por estas actividades pueda suponer un riesgo para la conservación, al facilitar la localización de especies, poblaciones o recursos naturales. El resto de actividades científicas y de investigación quedan sujetas a comunicación previa, a efectos de control y seguimiento.

El Decreto ha desaprovechado la oportunidad de ofrecer un procedimiento administrativo que impulse las labores de investigación para desarrollar nuevos modelos de gestión de los espacios naturales. El conocimiento científico es la clave para dar a conocer la riqueza de nuestros espacios naturales, pero necesita del apoyo de la Administración autonómica para poder hacer frente a los desafios que suponen estos estudios. Limitar la exigencia de autorización en este ámbito podría traducirse en un avance más relevante en los descubrimientos sobre los ecosistemas y las especies que albergan. También vinculada al mejor conocimiento de estos espacios naturales se encuentra el denominado "saber local", los conocimientos que los habitantes del entorno se han transmitido de generación en generación y la propia experiencia en su relación con el territorio. El intercambio de información entre el ámbito científico y la pobla-

\footnotetext{
${ }^{61}$ En base a este precepto, quedan sometidas a autorización: i) en el Parque Natural Sierra de Aracena y Picos de Aroche: la introducción de nuevas variedades de castaño con fines productivos; ii) en el Parque Natural de Cabo de Gata-Níjar: cualquier tipo de transformación agrícola que implique sustitución de cultivos herbáceos a leñosos, y las prácticas de desinfección de suelos cuando se utilicen productos fitosanitarios; iii) en el Parque Natural Doñana: el aprovechamiento de eneas, castañuelas y juncos, que solo podrá autorizarse fuera de la época de nidificación de aves acuáticas, y el aumento temporal de la carga ganadera sobre lo establecido en el correspondiente plan de aprovechamiento o documento de gestión ganadera aprobado.
} 
ción local supone un enriquecimiento mutuo que redunda en el fin básico: la mejor conservación y respeto del espacio protegido. En este sentido sería oportuno incluir a representantes de las localidades vecinas en los equipos científicos para que pudieran colaborar e intercambiar experiencias, creando de esta forma un flujo de conocimientos recíproco ${ }^{62}$.

\section{Competencias de las Juntas Rectoras de los Parques Naturales y de las Consejerías implicadas}

El modelo de gobernanza ambiental que se trata de implantar desde las instituciones autonómicas andaluzas pasa por una reestructuración de los órganos con competencia en la gestión y ordenación de los parques naturales. La reforma en la gestión de los parques quedaría incompleta sin la mejora de las estructuras de gobierno y sus competencias.

Desde todos los foros se incide en esta necesidad, así desde Europarc-España se apuesta por mejorar la gobernabilidad de las áreas protegidas y la eficacia de las estructuras de gobierno; además de intensificar la participación de todos los interesados, promover la equidad y la participación en los beneficios, y garantizar la sostenibilidad financiera. Con el fin de alcanzar estos fines se propone realizar un análisis de las estructuras de gobierno en los sistemas de espacios protegidos en lo que respecta a su composición, eficacia, participación y capacidades de decisión ${ }^{63}$. En la misma línea se ha manifestado el Informe "Andalucía +20" que opta por fortalecer los órganos colegiados existentes, en especial las Juntas Rectoras, con fórmulas que mejoren su eficiencia y que sigan los cauces legales establecidos para la participación ${ }^{64}$.

El nuevo Decreto andaluz establece novedades en cuanto a las funciones de los órganos de gobierno y gestión de los Parques Naturales. Se amplían las funciones de las Juntas Rectoras de los Parques Naturales, reguladas en el Decreto 239/1997, de 15 de octubre, que regula su constitución, composición y funciones.

La redacción originaria de las funciones que corresponden a estas Juntas se regulaba en el artículo segundo del Decreto 239/1997; este precepto establece

\footnotetext{
${ }^{62}$ Sobre la importancia de este saber local se ha pronunciado CONSEJERÍA DE MEDIO AMBIENTE DE LA JUNTA DE ANDALUCÍA, $A \mathcal{N}+20$. op. cit., pp. 94 y 95 .

${ }^{63}$ EUROPARC-ESPAÑA, op. cit., pp.33.

${ }^{64}$ CONSEJERÍA DE MEDIO AMBIENTE DE LAJUNTA DE ANDALUCÍA, AN +20. op. cit., pp. 102.
} 
una serie de competencias genéricas que se atribuyen a este órgano, funciones de control, vigilancia y participación ciudadana, velar por el cumplimiento de la normativa reguladora del Parque, proponer normas para una eficaz defensa de sus valores ecológicos, promover el desarrollo sostenible, en el interior y en el entorno del Parque, y realizar cuantas gestiones necesarias para el espacio natural de conformidad con lo dispuesto en el artículo 20.1 de la Ley 2/1989, de 18 de julio. Estos órganos colegiados también ostentan competencia para promover normas y cualquier otro tipo de iniciativas que consideren beneficiosas para la preservación y disfrute del Parque Natural.

Este precepto también incluye una serie de funciones específicas que se pueden agrupar en competencias de gestión y planificación. Entre los cometidos más relevantes de las Juntas Rectoras se encuentra informar el PORN, y aprobar provisionalmente el PRUG y sus revisiones, así como colaborar en el cumplimiento de los objetivos que se fijen mediante el PORN y el PRUG. También en el ámbito de la planificación, el texto originario del Decreto 239/1997 atribuía competencia a estos órganos para emitir informe sobre los planes que afecten a los recursos naturales del Parque y a la conservación de sus valores singulares. Esta competencia se ha visto ampliada por la modificación introducida en esta norma a través del Decreto $15 / 2011^{65}$; gracias a esta nueva redacción, las Juntas Rectoras también serán competentes para emitir informe "en relación con los supuestos a los que se refiere el artículo 15 bis 2 de la Ley 2/1989, de 18 de julio, por la que se aprueba el Inventario de Espacios Naturales Protegidos de Andalucía y se establecen medidas adicionales para su protección"

${ }^{65}$ La disposición final decimotercera del Decreto 15/2011 modifica el párrafo e) del art. 2.2 del Decreto 239/1997, de 15 de octubre, por el que se regula la constitución, composición y funciones de las Juntas Rectoras de los Parques Naturales.

${ }^{66} \mathrm{El}$ art. 15 bis 2 de la Ley 2/1989, de 18 de julio, por la que se aprueba el Inventario de Espacios Naturales Protegidos de Andalucía y se establecen medidas adicionales para su protección, dispone: "En el supuesto de que, por razones ambientales, la normativa de los Planes de Ordenación de los Recursos Naturales, los Planes Rectores de Uso y Gestión y los Planes de Ordenación del Territorio de Ámbito Subregional establezcan una prohibición que impida la realización de infraestructuras lineales, estas podrán implantarse siempre que resulten autorizables de acuerdo con los procedimientos de prevención y control ambiental previstos en la Ley 7/2007, de 9 de julio, de Gestión Integrada de la Calidad Ambiental, sin perjuicio de lo establecido en el artículo 45 de la Ley 42/2007, de 13 de diciembre, del Patrimonio Natural y la Biodiversidad, para los espacios protegidos incluidos en la Red Natura 2000. En el caso de que por razón de su naturaleza y características las citadas infraestructuras lineales no estuvieran sometidas a procedimientos de prevención y control ambiental, conforme a lo previsto en el Anexo I de la Ley de Gestión Integrada de la Calidad Ambiental, el procedimiento a seguir para su autorización será el establecido para la calificación ambiental en la Sección V del Capítulo II del Título III de dicha ley". 
Por tanto, las Juntas Rectoras de los Parques Naturales son competentes para emitir informe sobre la realización de infraestructuras lineales que puedan ser autorizadas según los procedimientos de prevención y control ambiental previstos en la Ley 7/2007 de 9 de julio, de Gestión Integrada de la Calidad Ambiental ${ }^{67}$, aún cuando por razones ambientales la normativa de los PORN, los PRUG y los Planes de Ordenación del Territorio de Ámbito Subregional establezcan una prohibición que impida la realización de este tipo de infraestructuras. Además de las limitaciones previstas en la Ley $7 / 2007$, hay que respetar las previsiones incluidas en la Ley 42/2007, de 13 de diciembre, del Patrimonio Natural y la Biodiversidad, para los espacios protegidos incluidos en la Red Natura $2000^{68}$; por lo que habrá que atender a las repercursiones de estos proyectos sobre los hábitat naturales y los hábitat de las especies, así como las alteraciones que puedan afectar a las especies que hayan motivado la designación de estas áreas.

${ }^{67}$ El objeto de la Ley 7/2007, según se encuentra definido en su art. 1, es "establecer un marco normativo adecuado para el desarrollo de la política ambiental de la Comunidad Autónoma de Andalucía, a través de los instrumentos que garanticen la incorporación de criterios de sostenibilidad en las actuaciones sometidas a la misma".

${ }^{68}$ El art. 45 de la Ley 42/2007, de 13 de diciembre, del Patrimonio Natural y la Biodiversidad dispone: "1. Respecto de las Zonas Especiales de Conservación y las Zonas de Especial Protección para las Aves, las Comunidades Autónomas fijarán las medidas de conservación necesarias, que respondan a las exigencias ecológicas de los tipos de hábitat naturales y de las especies presentes en tales áreas, que implicarán: a) Adecuados planes o instrumentos de gestión, específicos a los lugares o integrados en otros planes de desarrollo que incluyan, al menos, los objetivos de conservación del lugar y las medidas apropiadas para mantener los espacios en un estado de conservación favorable; b) Apropiadas medidas reglamentarias, administrativas o contractuales; 2. Igualmente las administraciones competentes tomarán las medidas apropiadas, en especial en dichos planes o instrumentos de gestión, para evitar en los espacios de la Red Natura 2000 el deterioro de los hábitat naturales y de los hábitat de las especies, así como las alteraciones que repercutan en las especies que hayan motivado la designación de estas áreas, en la medida en que dichas alteraciones puedan tener un efecto apreciable en lo que respecta a los objetivos de la presente Ley; 3. Los órganos competentes deberán adoptar las medidas necesarias para evitar el deterioro o la contaminación de los hábitat fuera de la Red Natura 2000; 4. Cualquier plan, programa o proyecto que, sin tener relación directa con la gestión del lugar o sin ser necesario para la misma, pueda afectar de forma apreciable a los citados lugares, ya sea individualmente o en combinación con otros planes o proyectos, se someterá a una adecuada evaluación de sus repercusiones en el lugar, que se realizará de acuerdo con las normas que sean de aplicación, de acuerdo con lo establecido en la legislación básica estatal y en las normas adicionales de protección dictadas por las Comunidades Autónomas, teniendo en cuenta los objetivos de conservación de dicho lugar. A la vista de las conclusiones de la evaluación de las repercusiones en el lugar y supeditado a lo dispuesto en el apartado 5 de este artículo, los órganos competentes para aprobar o autorizar los planes, programas o proyectos sólo podrán manifestar su conformidad con los mismos tras haberse asegurado de que no causará perjuicio a la integridad del lugar en cuestión y, si procede, tras haberlo sometido a información pública; 5 . Si, a pesar de las conclusiones negativas de la evaluación de las repercusiones sobre el lugar y a falta de soluciones alternativas, debiera realizarse un plan, programa o proyecto por razones imperiosas de interés público de primer orden, incluidas razones de índole social 
La norma andaluza también incluye referencias al fortalecimiento de los titulares de las Consejerías en la gestión de los parques naturales. La disposición final decimocuarta del Decreto 15/2011 habilita a las Consejerías con competencias en la materia para el desarrollo y ejecución de las disposiciones de la norma andaluza. Se realiza una mención conjunta a una Orden de las Consejerías de Medio Ambiente y Turismo, Comercio y Deporte para la regulación de las obligaciones y condiciones medioambientales para la práctica de las actividades de turismo activo y ecoturismo.

En segundo lugar, se establece una cláusula abierta mediante la que se habilita al Consejero de Medio Ambiente para el desarrollo y la ejecución de lo previsto en el Decreto andaluz. En el ámbito de los procedimientos de autorización y comunicación previa, el titular de esta Consejería ostentará competencias para modificar las actividades sujetas al procedimiento abreviado de autorización, incluir nuevas actividades en el catálogo de las sujetas a autorización o comunicación previa, y excepcionar del régimen de autorización y someter a comunicación previa las actividades de uso público, turismo activo y ecoturismo, e investigación.

En lo que respecta a las actuaciones sobre suelo no urbanizable las competencias hacen referencia a la capacidad para establecer las condiciones técni-

o económica, las Administraciones Públicas competentes tomarán cuantas medidas compensatorias sean necesarias para garantizar que la coherencia global de Natura 2000 quede protegida. La concurrencia de razones imperiosas de interés público de primer orden sólo podrá declararse para cada supuesto concreto: a) Mediante una ley; b) Mediante acuerdo del Consejo de Ministros, cuando se trate de planes, programas o proyectos que deban ser aprobados o autorizados por la Administración General del Estado, o del órgano de Gobierno de la Comunidad Autónoma. Dicho acuerdo deberá ser motivado y público. La adopción de las medidas compensatorias se llevará a cabo, en su caso, durante el procedimiento de evaluación ambiental de planes y programas y de evaluación de impacto ambiental de proyectos, de acuerdo con lo dispuesto en la normativa aplicable. Dichas medidas se aplicarán en la fase de planificación y ejecución que determine la evaluación ambiental. Las medidas compensatorias adoptadas serán remitidas, por el cauce correspondiente, a la Comisión Europea; 6. En caso de que el lugar considerado albergue un tipo de hábitat natural y/o una especie prioritaria, señalados como tales en los anexos I y II , únicamente se podrán alegar las siguientes consideraciones: a) Las relacionadas con la salud humana y la seguridad pública; b) Las relativas a consecuencias positivas de primordial importancia para el medio ambiente; c) Otras razones imperiosas de interés público de primer orden, previa consulta a la Comisión Europea; 7. La realización o ejecución de cualquier plan, programa o proyecto que pueda afectar negativamente a especies incluidas en los anexos II o IV que hayan sido catalogadas como en preligro de extinción, únicamente se podrá llevar a cabo cuando, en ausencia de otras alternativas, concurra alguna de las causas citadas en el apartado anterior. La adopción de las correspondientes medidas compensatorias se llevará a cabo conforme a lo previsto en el apartado 5; 8. Desde el momento en que el lugar figure en la lista de Lugares de Importancia Comunitaria aprobada por la Comisión Europea, éste quedará sometido a lo dispuesto en los apartados 4, 5 y 6 de este artículo; 9. Desde el momento de la declaración de una ZEPA, ésta quedará sometida a lo dispuesto en los apartados 4 y 5 de este artículo".

Revista Andaluza de Administración Pública

ISSN: 0034-7639, núm. 81, Sevilla, septiembre-diciembre (2011), págs. 101-148 
cas de ejecución de las actuaciones en el suelo no urbanizable de los parques naturales; así como la aprobación de modelos normalizados para las solicitudes, de autorizaciones o comunicaciones previas de actuaciones, en suelo no urbanizable dentro de los parques naturales.

En el ámbito de la planificación urbanística las competencias son de gran relevancia, ya que el titular de la Consejería será el responsable de adecuar las previsiones sobre parámetros de edificación y características constructivas de los PORN y PRUG a las modificaciones de la planificación urbanística con evaluación ambiental favorable y el plan urbanístico definitivo aprobado. Por último también cabe señalar la competencia para actualizar los límites de los parques naturales, y regular las condiciones y limitaciones de las actividades de uso público.

\section{CONSIDERACIONES FINALES}

El Decreto 15/2011 es una norma vinculada a las polémicas, han sido necesarios cuatro borradores para que finalmente se aprobara un texto con carácter definitivo que aún no ha logrado el consenso de todos los implicados. Las principales dudas que han surgido en torno a esta norma ponen de relieve su posible contradicción con la Ley 42/2007 del Patrimonio Natural y de la Biodiversidad, ley básica estatal ${ }^{69}$, en tanto a la relación entre los planes generales de ordenación urbana de los municipios y las normas de protección de los parques (PORN y PRUG); así como sobre las competencias de los Consejeros en cuanto a la modificación de los PORN y PRUG. En este sentido se han manifestado el Defensor del Pueblo Andaluz y diversas asociaciones ecologistas ${ }^{70}$.

${ }^{69}$ La Disposición final segunda de la Ley 42/2007 establece: "1.Esta Ley tiene carácter de legislación básica sobre protección del medio ambiente, de conformidad con lo dispuesto en el artículo 149.1.23 de la Constitución, salvo las siguientes disposiciones: el artículo 68, que constituye legislación sobre comercio exterior dictada al amparo del artículo 149.1.10 de la Constitución; y la disposición adicional sexta, que constituye competencia exclusiva en materia de relaciones internacionales dictada al amparo del artículo 149.1.3; 2. No son básicos el artículo 72.2 y la disposición adicional primera, que serán sólo de aplicación a la Administración General del Estado, a sus Organismos Públicos y a las Agencias Estatales".

${ }^{70}$ El Defensor del Pueblo Andaluz se pronunció sobre el Proyecto de Decreto autonómico a través de su Resolución formulada en la queja 10/3015 dirigida a la Consejería de Medio Ambiente, relativa al Proyecto de modificación del régimen de planificación de los usos y actividades en los parques naturales de Andalucía. Esta queja también se ha incluido en el Informe Anual 2010, pp. 20-23. Si bien hay que tener presente que esta Resolución hacía referencia al Proyecto, que posteriormente sufrió modificaciones, se establecen algunas afirmaciones que son de aplicación al texto definitivo del Decreto. En su interpretación del art. 18.2 de la Ley 42/2007, el Defensor del Pueblo establece: "De acuerdo con lo anterior, el planeamiento urbanístico de los municipios insertos dentro de los Parques Naturales únicamente puede adap- 
En primer lugar, cabe remitirse a lo dispuesto en el artículo 18.2 de la Ley 42/2007, donde se afirma: "Cuando los instrumentos de ordenación territorial, urbanística, de recursos naturales y, en general, física, existentes resulten contradictorios con los Planes de Ordenación de Recursos Naturales deberán adaptarse a éstos. En tanto dicha adaptación no tenga lugar, las determinaciones de los Planes de Ordenación de Recursos Naturales se aplicarán, en todo caso, prevaleciendo sobre dichos instrumentos" $"$.

A la vista de lo expuesto consideramos que las previsiones del Decreto ofrecen una vía alternativa a la prevalencia de los PORN y PRUG sobre el planeamiento urbanístico, que resulta incompatible con la legislación estatal básica.

tarse a las disposiciones contenidas en los PORN, de forma que cualquier contradicción entre ambas regulaciones debe ser resuelta en favor de lo reglado en la normativa reguladora de los espacios naturales protegidos. En cuanto a la adaptación en sí, la misma debe constituir una acomodación perfecta del contenido de la norma urbanística en la norma del PORN, de manera que no cabría entender como adaptada una norma urbanística que, a pesar de haber seguido todos los trámites formales para su aprobación, incluido el de prevención ambiental, contenga disposiciones que resulten contradictorias con lo reglado en el PORN correspondiente. En tales casos, entraría en juego el inciso segundo del transcrito apartado segundo del artículo 18 de la Ley 42/2007, de forma que las determinaciones del Plan de ordenación de los Recursos Naturales se aplicarían prevaleciendo sobre el instrumento urbanístico".

${ }^{71}$ Sin perjuicio del análisis que hemos realizado en la primera parte de este estudio, debemos remitirnos de nuevo al artículo 2, a la disposición transitoria segunda y a la disposición final decimocuarta del Decreto y esquematizar su contenido: a) La planificación de la ordenación de los recursos naturales de los parques naturales de Andalucía corresponde al PORN de cada uno de los parques y al contenido del Decreto 15/2011. Los PORN y los PRUG de cada parque prevalecen sobre el Decreto en las siguientes materias: prohibiciones, limitaciones y condiciones específicas que estén establecidas de manera particular para las zonas de reserva, de regulación especial y de regulación común, en atención a los valores a proteger y a las características singulares de cada espacio. El Decreto 15/2011 prevalece sobre las normas generales previstas en los PORN y los PRUG; b) Los PORN de cada parque serán competentes para realizar la zonificación y regulación de usos compatibles con los objetivos de conservación del patrimonio natural y de la biodiversidad, y vincularán a la planificación urbanística sobre la que deberán prevalecer en caso de contradicción. En este apartado se cita expresamente al artículo 18.2 de la Ley 42/2007, al entender que con esta previsión se respeta su contenido. Los PORN de cada parque natural establecerán las normas particulares de regulación de usos y actividades compatibles con los objetivos de conservación. Este régimen particular y el régimen general previsto en el Decreto constituyen la planificación integrada de usos y actividades de los espacios naturales; c) Los planes urbanísticos que obtengan el informe favorable de valoración ambiental de la Consejería con competencias sobre medio ambiente relevarán a los PORN y PRUG en lo que respecta a parámetros de edificación y características constructivas. Estos planes urbanísticos deberán establecer un contenido mínimo para los distintos usos permitidos en suelo no urbanizable que incluye referencias sobre: las parcelas mínimas para las edificaciones y construcciones, las distancias mínimas y las características edificatorias externas; además de las características o condiciones específicas para la implantación de las edificaciones y construcciones de interés público en suelo no urbanizable; d) El Consejero de Medio Ambiente ostenta la competencia para modificar las normas generales de los PORN y PRUG sobre parámetros de edificación y características constructivas, con el fin de adecuarlas a las previsiones de la planificación urbanística aprobada previa evaluación ambiental favorable.

Revista Andaluza de Administración Pública

ISSN: 0034-7639, núm. 81, Sevilla, septiembre-diciembre (2011), págs. 101-148 
El Decreto 15/2011 crea una fórmula que permite eludir la supremacía del marco regulador del PORN y el PRUG de los parques naturales, y para ello se sirve de la previa evaluación ambiental favorable otorgada por la Consejería de Medio Ambiente; además de regular expresamente la posibilidad de adaptar el PORN y el PRUG a la planificación urbanística cuando exista contradicción, y de forma unilateral por parte del Consejero de Medio Ambiente. Si bien es cierto que se establecen una serie de limitaciones, como el contenido mínimo que debe comprender la planificación urbanística y el sometimiento a la zonificación realizada por el PORN y PRUG, estos controles no impiden que exista contradicción entre la regulación básica del Estado y la norma andaluza.

Cabe recordar que el Gabinete Jurídico de la Junta de Andalucía emitió, con fecha 21 de julio de 2010, un informe favorable del Proyecto de Decreto. A pesar de esta valoración positiva, se solicitó que en la redacción se dejara patente que los distintos planes urbanísticos de los municipios debían supeditarse a los PORN y los PRUG de cada parque. El Gabinete Jurídico también se pronunció sobre las excepciones relativas a los parámetros de edificación y características constructivas y sostuvo que el informe de valoración ambiental garantizaba la salvaguarda de los valores medioambientales. Por su parte, el Dictamen del Consejo Consultivo realizó varias correcciones de carácter técnico.

A pesar de estas valoraciones, consideramos que el texto definitivo del Decreto no es claro en lo que respecta a la supremacía absoluta de los PORN y PRUG, y la salvaguarda de los valores ambientales a través de informe de valoración ambiental no puede ser óbice para el cumplimiento de la legislación estatal básica. Un nuevo modelo en la gestión de los parques naturales exige una reforma completa del marco normativo autonómico, y una regulación por Decreto no es la vía adecuada para incorporar novedades que contradicen las disposiciones vigentes con rango de ley. Si la voluntad del legislador autonómico es llevar a cabo la citada reforma, el esquema de actuación requiere una modificación del modelo de gestión de los parques naturales y de las normas sobre planificación urbanística.

En este contexto consideramos que la norma andaluza ha permitido reabrir un debate que nunca ha llegado a solventarse, y que sin duda necesita de nuevas decisiones sobre el futuro de los parques naturales de la Comunidad Autónoma. La Administración autonómica ha mostrado sus preferencias sobre la línea de actuación a seguir, pero no ha concretado los instrumentos necesarios ni ha planteado la reforma completa exigible. Como se ha puesto de manifies- 
to a lo largo de este estudio, el actual modelo de gestión de los parques naturales andaluces se encuentra obsoleto, por lo que resulta básica una reforma que actúe como revulsivo. La realidad ha puesto de relieve que los habitantes de los municipios en los que se ubican los parques naturales adoptan una actitud pasiva en estos espacios protegidos.

Las limitaciones y prohibiciones a las que obliga la protección y conservación del entorno condiciona el desarrollo socioeconómico de estos municipios, en su mayor parte rurales, que observan la declaración de parque natural o la extensión de sus límites como un lastre a sus posibilidades de futuro ${ }^{72}$. Los parques naturales parece que sólo son admirados por los visitantes que no ven condicionados su día a día por estas figuras de protección. La oposición de los grupos ecologistas a esta norma parece reabrir el eterno debate entre la explotación económica de los parques naturales y su protección y conservación. Por una lado los municipios valoran negativamente la creación de un parque natural en su territorio a causa de las limitaciones que ocasiona esta declaración; por otro lado, los ecologistas desconfian de las competencias urbanísticas municipales sobre los parques naturales porque consideran que darían lugar a un modelo urbanístico que comprometería la existencia misma de los parques.

En un tema central en el desarrollo territorial andaluz como es la gestión de los parques naturales, el Decreto no ha actuado como la norma de consenso deseable. Las voces que se han alzado contra la norma andaluza ponen el acento en las dificultades que puede ocasionar que los Ayuntamientos puedan adoptar decisiones urbanísticas en el territorio de los parques naturales. No obstante, consideramos que esta opción no tiene por qué configurarse como negativa en todas sus perspectivas.

La finalidad última de dotar a los Ayuntamiento de competencias reales sobre el esquema urbanístico de los parques naturales podría ser positiva; incluso permitiría que la población local participara de forma activa en la gestión de los parques. Si el legislador andaluz establece unos parámetros máximos y

\footnotetext{
72 En este sentido se han pronunciado las conclusiones del Seminario Internacional celebrado en abril de 2010 bajo el título El Desafio de la Gestión de los Espacios Naturales de Andalucía en un mundo cambiante. Una cuestión de valores. En las conclusiones de la mesa que analizó la dimensión socioeconómica en la gestión de los espacios ntaruales, se afirma: "El desarrollo de las planificaciones territoriales se debe enfocar a través de los grupos líderes locales ya establecidos en el territorio, en estrecha colaboración con los agentes sociales, económicos y administrativos del entorno. La experiencia de estos años nos revela que los distintos agentes y población local han tenudo un papel pasivo en los planes llevados a cabo por la administración lo que provoca que no asuman dichos planes como propios, lo que nos demuestra que es necesario utilizar los agentes locales en el territorio para que colaboren con la administración y den una visión integral".
} 
mínimos que garanticen la conservación y protección de los parques naturales, los Ayuntamientos podrían ejercer un conjunto de competencias urbanísticas sin que ello supusiera una merma de los valores ambientales a proteger.

El Decreto andaluz ha dado algunos tímidos pasos en el sentido de potenciar el desarrollo socioeconómico de los municipios cuyo término municipal comprenda un parque natural, apoyándose en las actividades que pueden realizarse en estos entornos protegidos; en esta misma línea ha otorgado ciertas competencias urbanísticas a los gobiernos municipales ${ }^{73}$. Además de la oposición, ya analizada, de algunos sectores cabe afirmar que el Decreto no ha llegado hasta el final de estas opciones, limitándose a esbozar un nuevo modelo de gestión que por su propio rango no se encontraba capacitado para implantar. Por ello, entendemos que desde los responsables autonómicos se han creado demasiadas expectativas sobre una norma que tan sólo debe completar y desarrollar las disposiciones vigentes, y que ha tratado de innovar más allá de las previsiones legales.

\section{BIBLIOGRAFÍA}

ARANA GARCÍA, E., y GRANADOS RODRÍGUEZ, J., en "La desaparición de las licencias en las actividades clasificadas incluidas en el ámbito de la directiva de servicios: el supuesto particular de la legislación ambiental andaluza”, Revista General de Derecho Administrativo, núm. 25, 2010.

CANO MURCIA, A., El nuevo régimen jurídico de las licencias de apertura, Ed. La Ley-El Consultor de los Ayuntamientos y de los Juzgados, Madrid, 2010. COMISIÓN EUROPEA, Manual sobre la transposición de la Directiva de servicios, Oficina de publicaciones oficiales de las Comunidades Europeas, Luxemburgo, 2007.

CONSEJERÍA DE MEDIO AMBIENTE, JUNTA DE ANDALUCÍA, Andalucía +20. El Desafio de la Gestión de los Espacios Naturales de Andalucía en un mundo cambiante. Una cuestión de valores, Junta de Andalucía, Sevilla, 2010.

\footnotetext{
${ }^{73}$ En las consideraciones finales del documento Andalucia +20 se afirma: "En el contexto del Cambio Global, el modelo de administración de los espacios naturales requiere una gestión adaptativa, unitaria y global del territorio, que rompa el modelo dual de una Andalucía protegida, con usos preferentes de conservación de la naturaleza, y de una Andalucía no protegida, con vocación preferente de usos enfocados al crecimiento económico. En ese nuevo modelo, en el que los espacios protegidos adquieren un nuevo significado, el concepto de espacio natural permite esa necesaria articulación entre la RENPA y el resto del territorio". CONSEJERÍA DE MEDIO AMBIENTE DE LA JUNTA DE ANDALUCÍA, $A \mathcal{N}+20$. op. cit., pp. 107.
} 
CONSEJERÍA DE MEDIO AMBIENTE, JUNTA DE ANDALUCÍA, Seminario Internacional: El Desafio de la Gestión de los Espacios Naturales de Andalucía en un mundo cambiante. Una cuestión de valores, Sevilla, 12-14 de abril de 2010.

DE LA CUADRA SALCEDO JANINI, T., ¿¿Quo vadis Bokestein? ¿Armonización o mera desregulación de la prestación de servicios?", Revista Española de Derecho Europeo, núm. 22, 2007, pp. 237-280.

DEFENSOR DEL PUEBLO ANDALUZ, Informe Anual 2010, Boletín Oficial del Parlamento de Andalucía, núm. 667, de 28 de abril de 2011.

EUROPARC-ESPAÑA, Programa de Trabajo para las áreas protegidas 2009-2013, Ed. FUNGOBE, Madrid, 2009.

FERNÁNDEZ, T. R., "Un nuevo Derecho Administrativo para el mercado interior europeo", Revista Española de Derecho Europeo, núm. 22, 2007, pp. 189-197.

FERNÁNDEZ TORRES, J., "La apertura de grandes establecimientos comerciales no puede quedar sujeta a consideraciones económicas (comentario a la STJUE de 24 de marzo de 2011, Comisión c. España, as. C-400/08)", Revista Aranzadi de Urbanismo y Edificación, núm. 23, 2011.

FERNÁNDEZ TORRES, J., "Regímenes de intervención administrativa: autorización, comunicación previa y declaración responsable", Revista catalana de dret públic, núm. 42, 2011.

JORDANO FRAGA, J., "Política ambiental de Andalucía" en LÓPEZ RAMÓN, F. (Coord), Observatorio de Políticas Ambientales 2007, Ministerio de Medio ambiente, Thomson-Aranzadi, Pamplona, 2007.

LAGUNA DE PAZ, J., "Controles administrativos para el acceso al mercado: autorizaciones, declaraciones responsables y comunicaciones previas", en VICENTE BLANCO, D., y RIVERO ORTEGA, R. (Dir.), Impacto de la transposición de la Directiva de servicios en Castilla y León, Consejo Económico y Social de Castilla y León, Valladolid, 2010.

LÓPEZ MENUDO, F., "La Ley de Ordenación Urbanística de Andalucía”, Fusticia administrativa: Revista de derecho administrativo, 2003, pp. 7-39.

LOZANO CUTANDA, B., "Ley omnibus: una revolución en las técnicas de intervención administrativa (silencio positivo, declaración responsable y comunicación previa)", Working Paper IE Law School, AJ8-161, 25 de marzo de 2010.

MELLADO RUIZ, L., "Directiva de servicios y simplificación administrativa: un paso adelante en la racionalización de la organización y actuación administrativas", Noticias de la Unión Europea. Monográfico: La Directiva de Servicios y su transposición al derecho español, núm. 317, junio 2011, pp. 73-86.

MUÑOZ MACHADO, S., "Ilusiones y conflictos derivados de la Directiva de Servicios", Revista General de Derecho Administrativo, núm. 21, 2009. 
PAREJO ALFONSO, L., "La desregulación de los servicios con motivo de la Directiva Bolkestein: la interiorización, con paraguas y en ómnibus de su impacto en nuestro sistema", El cronista del Estado Social y Democrático de Derecho, núm. 6, 2009, pp. 34-41.

RASTROLLO SUÁREZ, J., "Directiva de servicios: urbanismo, medio ambiente y agricultura", Revista de derecho urbanístico y medio ambiente, núm. 259, 2010, pp. $135-172$.

RAZQUIN LIZARRAGA, J., "El impacto de la Directiva de Servicios en el procedimiento administrativo: autorización, declaración responsable y comunicación", Revista jurídica de Navarra, núm. 49, 2010.

REINOSO CARRIEDO, A., "La Directiva de servicios. Dificultades para su transposición”, El Consultor de los Ayuntamientos y de los Fuzgados, núm. 17, 2009, pp. 2457-2466.

RIVERO ORTEGA, R., La transposición de la Directiva de Servicios en España, Civitas, Madrid, 2009.

RIVERO ORTEGA, R., "Reformas de Derecho Administrativo para 2010: la difícil transposición de la Directiva de Servicios en España", Revista Aragonesa de Administración Pública, núm. 34, 2009, pp. 51-80.

RUBALCABA, L. y VISINTIN, S., "The internal market for services", en RUBALCABA, L., The new service economy, Edward Elgar Publishing, Cheltenham, Reino Unido, 2007.

SÁNCHEZ ARMAS, T., "El régimen de autorizaciones en la Directiva de Servicios. ¿Hacia un nuevo Derecho Administrativo", en Retos y oportunidades para la transposición de la Directiva de Servicios, Libro Marrón, Círculo de Empresarios, Madrid, 2009, pp. 405-432.

SÁNCHEZ GUTIÉRREZ, M., "La transposición de la Directiva de Servicios al Ordenamiento español. Especial referencia a los cambios previstos en la regulación del sector del gas natural", Revista General de Derecho Administrativo, núm. 22, 2009.

SANZ RUBIALES, I., "Medio Ambiente y Directiva de Servicios en Castilla y León", en VICENTE BLANCO, D., y RIVERO ORTEGA, R. (Dir.), Impacto de la transposición de la Directiva de servicios en Castilla y León, Consejo Económico y Social de Castilla y León, Valladolid, 2010.

VERAJURADO, D., "Evolución e integración de la perspectiva ambiental en la legislación y su influencia en el ámbito local", Fábega, núm. 91, 2002 (Ejemplar dedicado a: Sostenibilidad y medio ambiente en la provincia de Málaga (II), coord. por Saturnino Moreno Borrell), pp. 75-92.

VILLAREJO GALENDE, H. y SALVADOR ARMENDARIZ, M.,"El complejo proceso de transposición de la Directiva de Servicios", en Informe Comunidades Autónomas 2008, Instituto de Derecho Público, Barcelona, 2009. 